Aus dem Institut für Pathologie

(Prof. Dr. med. P. Ströbel)

der Medizinischen Fakultät der Universität Göttingen

\title{
Optimierte expressionsbasierte Mikrodissektion an Formalin-fixiertem Gewebe des Adenokarzinoms der Lunge
}

\author{
INAUGURAL-DISSERTATION \\ zur Erlangung des Doktorgrades \\ der Medizinischen Fakultät der \\ Georg-August-Universität zu Göttingen
}

vorgelegt von

Thurid Regula Hofmann

aus

Hannover

Göttingen 08.04.2021 
Dekan:

Referent:

Ko-Referent:

Drittreferent:
Prof. Dr. med. W. Brück

Prof. Dr. med. P. Ströbel

Prof. Dr. med. Peter Burfeind

Prof. Dr. med. Martin Oppermann

Datum der mündlichen Prüfung: 20.04.2021 
Hiermit erkläre ich, die Dissertation mit dem Titel "Optimierte expressionsbasierte Mikrodissektion an Formalin-fixiertem Gewebe des Adenokarzinoms der Lunge" eigenständig angefertigt und keine anderen als die von mir angegebenen Quellen und Hilfsmittel verwendet zu haben.

Göttingen, den 08.04.2021

(Unterschrift) 


\section{Inhaltsverzeichnis}

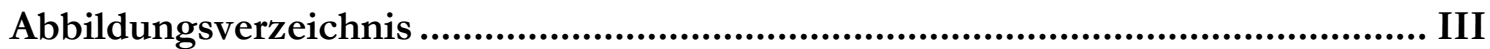

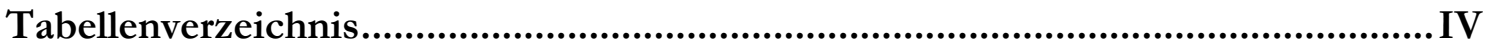

Abkürzungsverzeichnis ..................................................................................... V

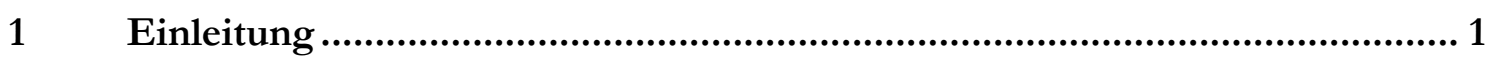

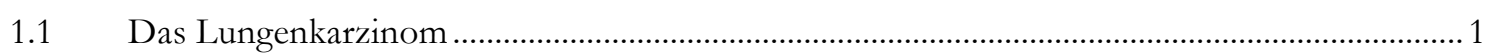

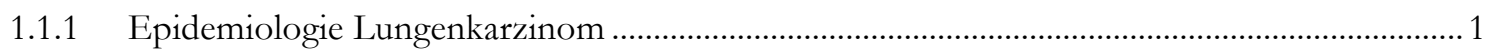

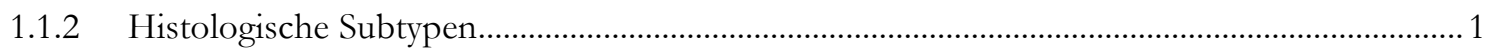

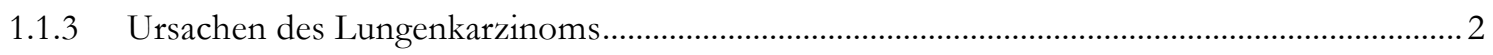

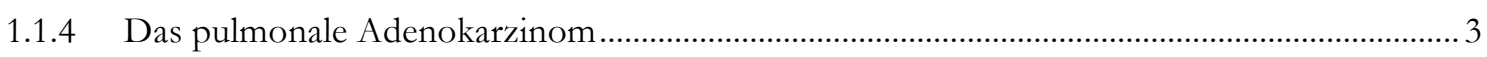

1.2 Bedeutung molekularer Subgruppen des Adenokarzinoms ...................................................... 3

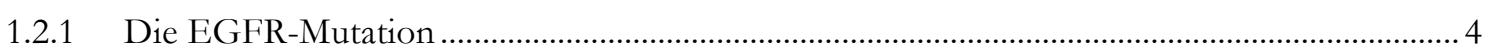

1.3 Tumorheterogenität als diagnostische Herausforderung............................................................ 6

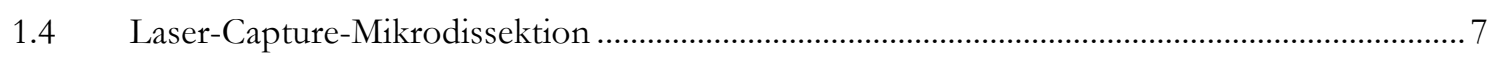

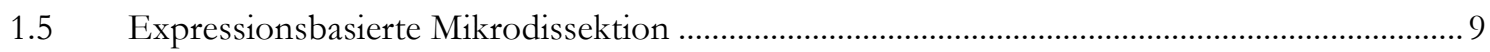

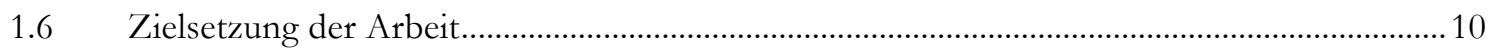

2 Material und Methoden.........................................................................12

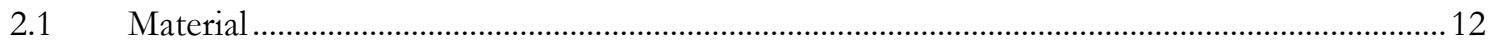

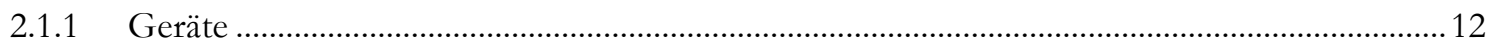

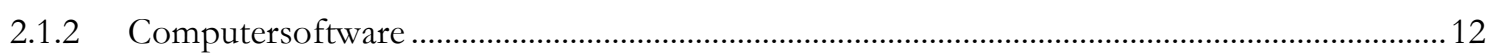

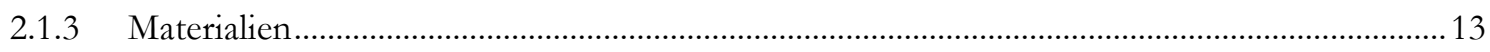

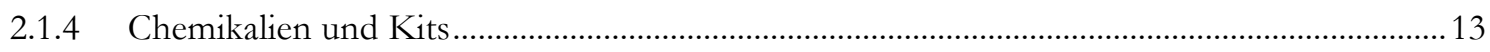

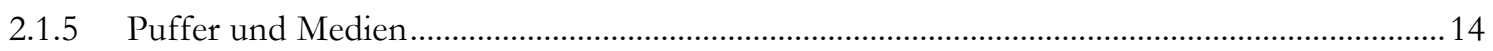

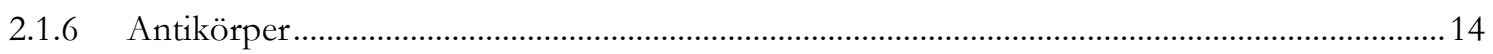

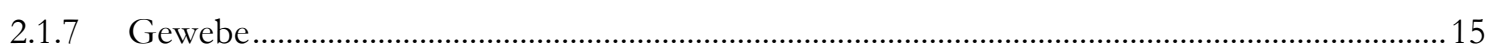

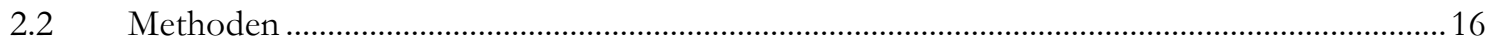

2.2.1 Probenvorbereitungen und immunhistochemische Färbungen ..................................................16

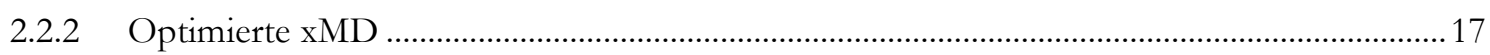

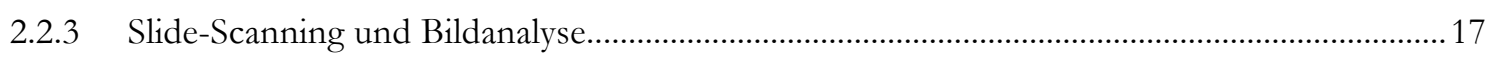

2.2.4 Isolation von der EVA-Membran und Analyse der DNA-Qualität ...........................................18

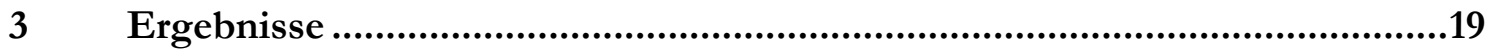

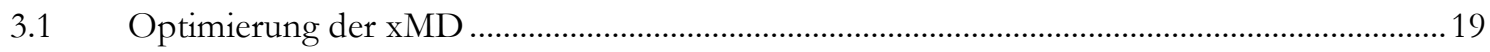

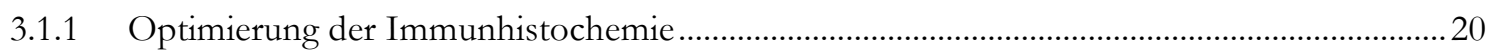

3.1.2 Vergleich von Vorbehandlung und Objektträgern ................................................................2

3.1.3 Optimierung der technischen Durchführung der xMD ...........................................................2

3.2 Vergleichende Bildanalyse von Gewebeproben vor und nach Mikrodissektion .....................24

3.3 DNA-Isolation von der EVA-Membran und Analyse ihrer Qualität.........................................26 


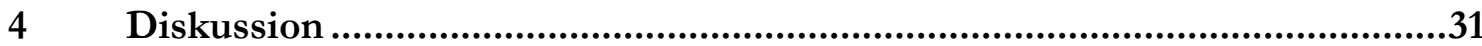

4.1 Optimierung der xMD am Adenokarzinom der Lunge..............................................................32

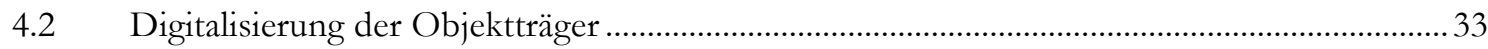

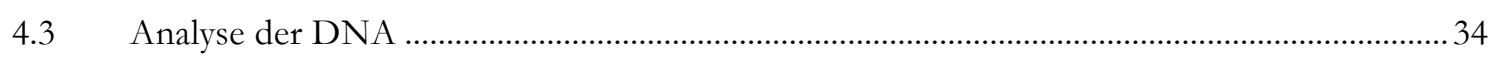

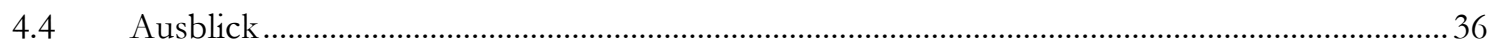

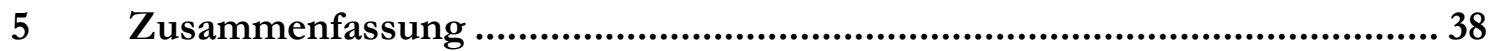

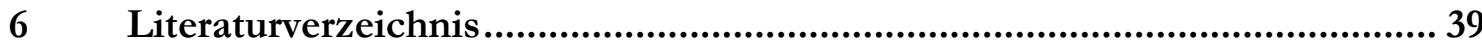




\section{Abbildungsverzeichnis}

Abbildung 1: Abbildung der Subtypen des Bronchialkarzinoms in Prozent..........................................2

Abbildung 2: Übersicht detektierter Mutationen des Adenokarzinoms der Lunge. ............................. 4

Abbildung 3: Schematische Abbildung des EGFR-Signalwegs......................................................... 5

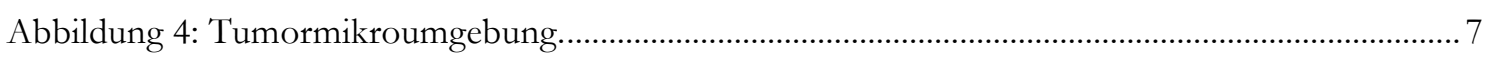

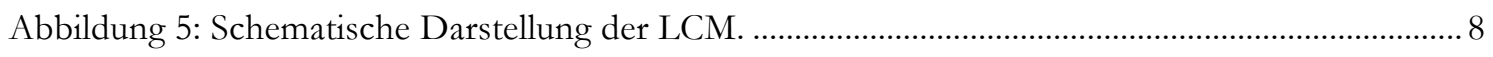

Abbildung 6: Schematisches Prinzip der xMD. ............................................................................... 9

Abbildung 7: Gewebesektion immunhistochemisch markiert (braune Kernfärbung) mit

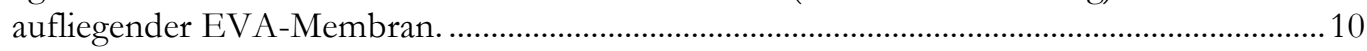

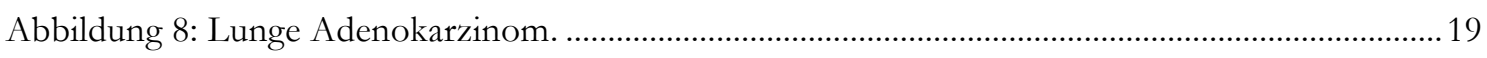

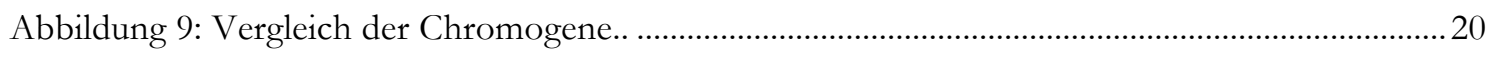

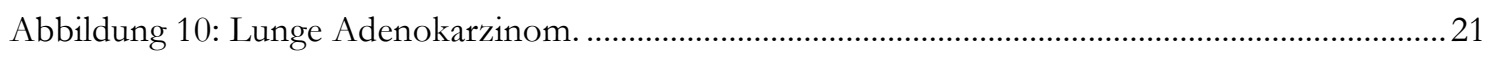

Abbildung 11: Vergleich der Objektträger nach Vorbehandlung. .......................................................22

Abbildung 12: Vergleich der Objektträger nach Vorbehandlung. ......................................................22

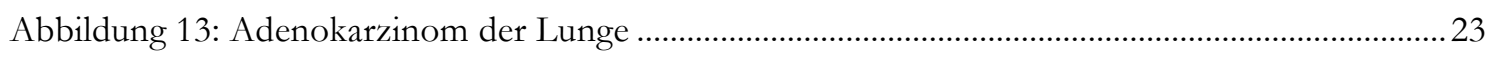

Abbildung 14: Schematische Darstellung der optimierten xMD. ........................................................24

Abbildung 15: Bildanalyse von mikrodisseziertem Gewebe des Adenokarzinoms der Lunge

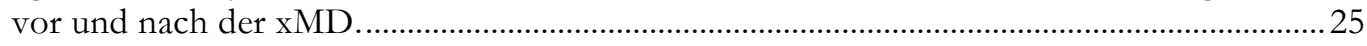

Abbildung 16: Streudiagramm der Intensität jede Pixels vor und nach der xMD..............................25

Abbildung 17: Simulierte Mikrodissektion von Lungenkrebsgewebe.. ...............................................26

Abbildung 18: Darstellung der Reproduzierbarkeit der xMD von Lungenkrebsgewebe...................27

Abbildung 19: DNA-Analyse von mikrodisseziertem Lungenkrebsgewebe. Elektropherogramm (Agilent Bioanalyzer 2100) der von der EVA-Membran isolierten

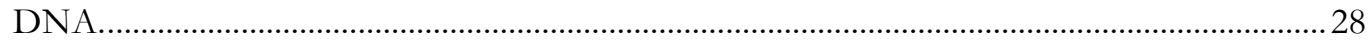

Abbildung 20: 1D Plots der Digitalen PCR des 91-BP-Amplikons zeigen die grünen positiven und die schwarzen negativen Banden der amplifizierten DNA.............................................29

Abbildung 21: Ratio von mutierter EGFR (E746-A750del) zu wild-typ-EGFR................................30 


\section{Tabellenverzeichnis}

Tabelle 1: Vergleich von Objektträgern. Unbeschichtet, Superfrost, Superfrost Plus. Vorbehandlung mit Citratpuffer und Protease K. + kennzeichnet eine gute Gewebehaftung nach der Vorbehandlung. + / zeigt Gewebeverluste an. - bezeichnet den Verlust des Gewebes.

Tabelle 1: Menge amplifizierbarer DNA per Probe. Vergleich von vier verschiedenen Proben des Adenokarzinoms der Lunge, getestet durch ein $91 \mathrm{bp}$.Amplikon und quantifiziert mittels digitaler PCR. Modifiziert nach Grafen et al. 2017. 


\section{Abkürzungsverzeichnis}

\begin{tabular}{|c|c|}
\hline Abb. & Abbildung \\
\hline ALK & Anaplastic lymphoma kinase \\
\hline BSA & Bovines Serumalbumin \\
\hline bp & Basenpaare \\
\hline CEA & Carcinom embryonales Antigen \\
\hline $\mathrm{CK}$ & Cytokeratin \\
\hline CYFRA & Cytokeratin Fragment \\
\hline $\mathrm{DAB}$ & Diaminobenzidin \\
\hline $\mathrm{ddH} 2 \mathrm{O}$ & Doppelt deionisiertes Wasser \\
\hline DNA & Desoxyribonukleinsäure \\
\hline EGF & Epidermal growth factor \\
\hline EGFR & Epidermal growth factor receptor \\
\hline $\mathrm{EU}$ & Europäische Union \\
\hline EVA-Membran & Ethylen-Venylacetat-Membran \\
\hline FFPE & Formalin-fixiert und in Paraffin-eingebettet \\
\hline HER & Human epidermal receptor \\
\hline IASLC & International association for the study of lung cancer \\
\hline $\mathrm{IHC}$ & Immunhistochemie \\
\hline KRAS & Kirsten Rat Sarcoma viral antigene \\
\hline LCM & Laser-Capture-Mikrodissektion \\
\hline LSAB & Labelled-Streptavidin-Biotin \\
\hline NSCLC & Non small cell lung cancer \\
\hline NSE & Neuronenspezifische Enolase \\
\hline OT & Objektträger \\
\hline p53 & Tumorprotein \\
\hline PCR & Polymerasekettenreaktion \\
\hline PET & Positronen-Emissions-Tomographie \\
\hline RNS & Ribonukleinsäure \\
\hline SCLC & Small cell lung cancer \\
\hline TRF-alpha & Transforming growth factor alpha \\
\hline Tris & Tris(hydroxymethyl)-aminomethan \\
\hline TNM-Stadium & Stadieneinteilung Tumor \\
\hline TTF-1 & Thyreoidaler Transkriptionsfaktor \\
\hline UICC & Union for International Cancer Control \\
\hline UV & Ultraviolett \\
\hline WHO & World Health Organisation \\
\hline $\mathrm{xMD}$ & Expressionsbasierte Mikrodissektion \\
\hline
\end{tabular}


Die Daten auf denen die vorliegende Arbeit basiert wurden teilweise publiziert:

Grafen et al. 2017 


\section{Einleitung}

\subsection{Das Lungenkarzinom}

\subsubsection{Epidemiologie Lungenkarzinom}

Das Lungenkarzinom ist weltweit der häufigste zum Tode führende Tumor des Mannes und der dritthäufigste bei der Frau. Die Inzidenz in der Europäischen Union liegt bei 52/100.000 pro Jahr, die Mortalität bei 48.7/100.000 pro Jahr (D’Addario und Felip 2009). In Deutschland starben 2015 45.220 Menschen an malignen Neubildungen der Bronchien und der Lunge, diese nehmen damit den dritten Rang der Todesursachen ein (s. Destatis). Es ist zu erwarten, dass das Bronchialkarzinom auch bei Frauen der häufigste zum Tode führende Tumor werden wird (Barnes et al. 2016). Die meisten Tumoren werden erst im fortgeschrittenen Stadium symptomatisch und dementsprechend spät diagnostiziert, was neben der hohen biologischen Aggressivität der Bronchialkarzinome zu einer niedrigen 5 Jahres-Überlebensrate von 15\% führt (Bob A und Bob K 2012).

\subsubsection{Histologische Subtypen}

Histologisch lassen sich Lungenkarzinome nach ihrem Erscheinungsbild in das Kleinzellige Lungenkarzinom (Small Cell Lung Cancer SCLC, 20\%) und das Nicht-Kleinzellige Lungenkarzinom (Non Small Cell Lung Cancer NSCLC, 80\%) unterteilen. Das NSCLC lässt sich in weitere in Subtypen unterteilen, worunter das Plattenepithelkarzinom und das Adenokarzinom je einen Anteil von 30\% einnehmen (Abbildung 1). Alle Lungenkarzinome entstehen vermutlich aus den auskleidenden epithelialen Zellen des Respirationstrakts.

Zur Stadieneinteilung der Lungenkarzinome wird die für viele weitere maligne Erkrankungen übliche TNM-Klassifikation der Union for International Cancer Control verwendet. Dabei werden die Größe und Ausbreitung des Primärtumors in Bezug zu benachbarten Strukturen (T-Status), der Befall von lokoregionären Lymphknoten (LStatus) und die Infiltration sonstiger Organe bzw. Fernmetastasierung (M-Status) berücksichtig. Das UICC-Stadium steht für die Verbindung dieser Kriterien und wird in die vier Klassen I, II, III und IV unterteilt. 


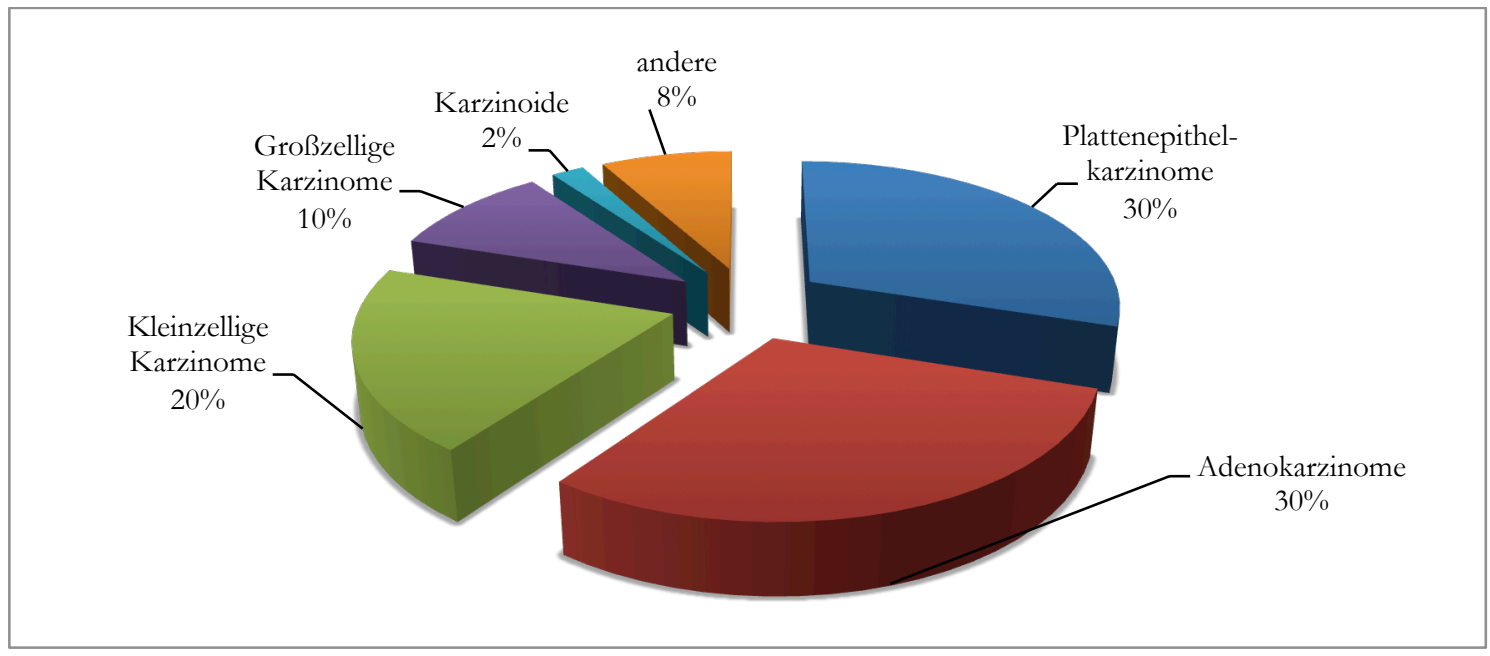

Abbildung 1: Abbildung der Subtypen des Bronchialkarzinoms in Prozent. Die histologische Aufteilung der wichtigsten Subtypen des Bronchialkarzinoms wird in Prozent dargestellt. Modifiziert nach Bob A und Bob K, 2012.

\subsubsection{Ursachen des Lungenkarzinoms}

Die Entstehung des Lungenkarzinoms erfolgt in einem mehrstufigen Prozess, der Karzinogenese.

Schon durch die British Doctors Studie ließ sich in den 1950er Jahren nachweisen, dass ein Zusammenhang zwischen der Entstehung des Lungenkarzinoms und dem Tabakkonsum besteht. Nach wie vor gilt das inhalative Zigarettenrauchen als wichtigster Risikofaktor für die Entstehung des Lungenkarzinoms (Alberg et al. 2013). Bis zu 90\% der Patienten mit Lungenkarzinomen sind Raucher (Böcker 2008). Tabakrauch enthält $>40$ kanzerogene Substanzen wie z.B polyzyklische Kohlenwasserstoffe und Oxidantien. Weitere Risikostoffe stellen unter anderem berufliche Karzinogene wie Quarz- und Nickelstäube, Arsen, Asbest sowie in der Luft zirkulierende Noxen dar (Bob A und Bob K 2012). Das Risiko steigt für alle histologischen Subtypen gleichermaßen um 10-35\%, wenngleich das Risiko für das Plattenepithelkarzinom und das SCLC aufgrund ihrer anatomisch zentralen Lage und der dort höchsten Konzentration an kanzerogenen Stoffen am höchsten ist. Die dauerhafte Exposition des Bronchien- und Lungenepithels mit karzinogenen Noxen führt zu Anpassungsreaktionen und genetischen Schäden in den Zellen.

In der europäischen Bevölkerung werden die vom Zigarettenkonsum unabhängigen Karzinome auf 15 \% geschätzt, wobei im asiatischen Raum die Zahl höher liegt. Bei diesen Tumoren zeigen sich gehäuft genetische Mutationen, die von den raucherinduzierten 
Mutationen abweichen (Sanchez-Cespedes et al. 2001; The Cancer Genome Atlas Research Network 2012).

Eine besondere Bedeutung bei der Entstehung des Adenokarzinoms hat die 2004 erkannte Mutation des Epidermal Growth Factor Receptors (EGFR); sie ist für 10-20\% der Adenokarzinome vor allem bei Nichtrauchern ursächlich und kann als onkogener Treiber durch ungehemmte Aktivierung zum malignen Wachstum der Zellen führen. (The Cancer Genome Atlas Research Network 2014). Der Signalweg des EGFR zeigt aber auch ein Ansprechen auf die medikamentöse Blockierung des Rezeptors (Cooper et al. 2013).

Ein weiterer Nichtraucher-assoziierter molekularer Subtyp des Adenokarzinoms ist die Translokation zwischen dem echinoderm microtubule associated protein-like 4 (EML4) und der anaplastic-lymphoma-kinase (ALK), die zur konstitutiven Aktivierung der Tyrosinkinase ALK führt. Die zielgerichtete Hemmung des Signalwegs kann auch hier therapeutisch genutzt werden.

\subsubsection{Das pulmonale Adenokarzinom}

In dieser Arbeit wurden ausschließlich Gewebe von pulmonalen Adenokarzinomen verwendet, weshalb auf diese im Folgenden detaillierter eingegangen wird.

Das Adenokarzinom der Lunge ist der häufigste Lungentumor (30\%). Es handelt sich um einen Tumor, der häufig in der Lungenperipherie aber auch zentral lokalisiert ist. Die WHO unterscheidet fünf histologische Typen (lepidische, azinäre, papilläre, mikropapilläre, solide Tumoren) und einige Varianten. Zu den histologischen Charakteristiken des Adenokarzinoms zählen u.a. Drüsenbildung und Schleimbildung. Histologisch handelt es sich meist um Mischformen der oben genannten Subtypen, der in der mikroskopischen Untersuchung dominierende Anteil ist zielführend für die Diagnose (Travis et al. 2015). Gängige immunhistochemische Marker des Adenokarzinoms sind das CK7, ein epithelialer Marker von Drüsen- und Übergangsepithelien der Thyreoidale Transkriptionsfaktor TTF1, sowie Napsin A, das in $>90 \%$ der primären Adenokarzinome der Lunge exprimiert wird (Warth et al. 2012).

\subsection{Bedeutung molekularer Subgruppen des Adenokarzinoms}

In der europäischen Bevölkerung wird der Anteil der Lungenkarzinome bei Nichtrauchern auf 15\% geschätzt, in der asiatischen Bevölkerung auf bis zu 32,4\% (Yano et al. 2011). 
Das pulmonale Adenokarzinom charakterisiert sich durch eine Vielzahl an molekularen Subgruppen mit spezifischen genetischen Mutationen. Durch sie werden Signalwege induziert oder verstärkt sowie Tumorsuppressor-Gene gehemmt, was zu unkontrolliertem Tumorwachstum führt (Cooper et al. 2013). Das Wissen über die genetische Mutation ist als prädiktiver Biomarker bedeutend für die Therapiesteuerung der Tumorerkrankung, dadurch wird sekundär die Prognose verbessert.

Diese Mutationen umfassen zu 10-20\% die Mutation des Epidermal Growth Factor Receptors (EGFR) im Adenokarzinom der Lunge. In 5\% ist die Translokation von echinodermmicrotubule associated protein-like 4 (EML4) und der anaplastic lymphoma kinase (ALK) als molekulare Subtypen vertreten (Sakai et al. 2013), letztere führt zur onkogenen Aktivierung der Kinasedomäne von ALK (Soda et al. 2007).

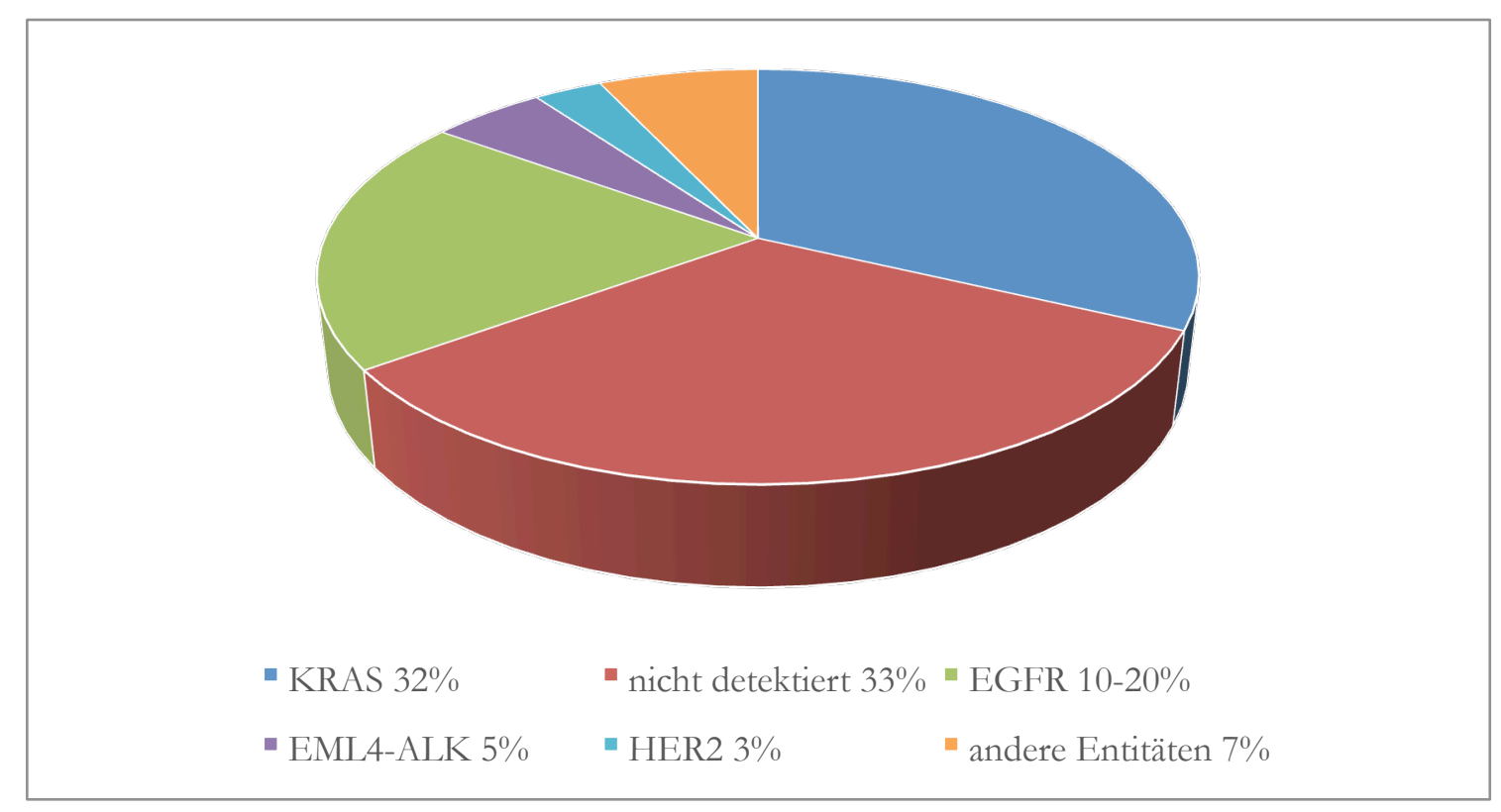

Abbildung 2: Übersicht detektierter Mutationen des Adenokarzinoms der Lunge. Modifiziert nach Daten von Cooper et al. 2013 und Sakai et al. 2013.

\subsubsection{Die EGFR-Mutation}

In dieser Arbeit wurde mit Gewebe eines EGFR-mutierten pulmonalen Adenokarzinoms gearbeitet, weshalb auf diese Veränderung detailierter eingegangen wird.

Der epidermal growth factor receptor (EGFR) gehört zu den Transmembranrezeptoren der epithelialen Wachstumsfaktoren (HER/ErbB-Familie) und war der erste Rezeptor, für den eine Kinaseaktivität nachgewiesen wurde (Wells 1999). Der Genlocus von EGFR liegt auf dem Chromosom 7p11.2 (Prabhakar 2015). EGFR kommt auf allen epithelialen Zellen sowie auf Gliazellen und glatten Muskulzellen vor. Er besteht aus einer extrazellulären Domäne, die Liganden bindet, einer Transmembrandomäne, sowie einer intrazellulären 
Tyrosinkinasedomäne, deren Signalweg Basisfunktionen der Zellen wie Zellwachstum und -differenzierung sowie Apoptose reguliert (Jorge et al. 2014) (siehe Abbildung 3).

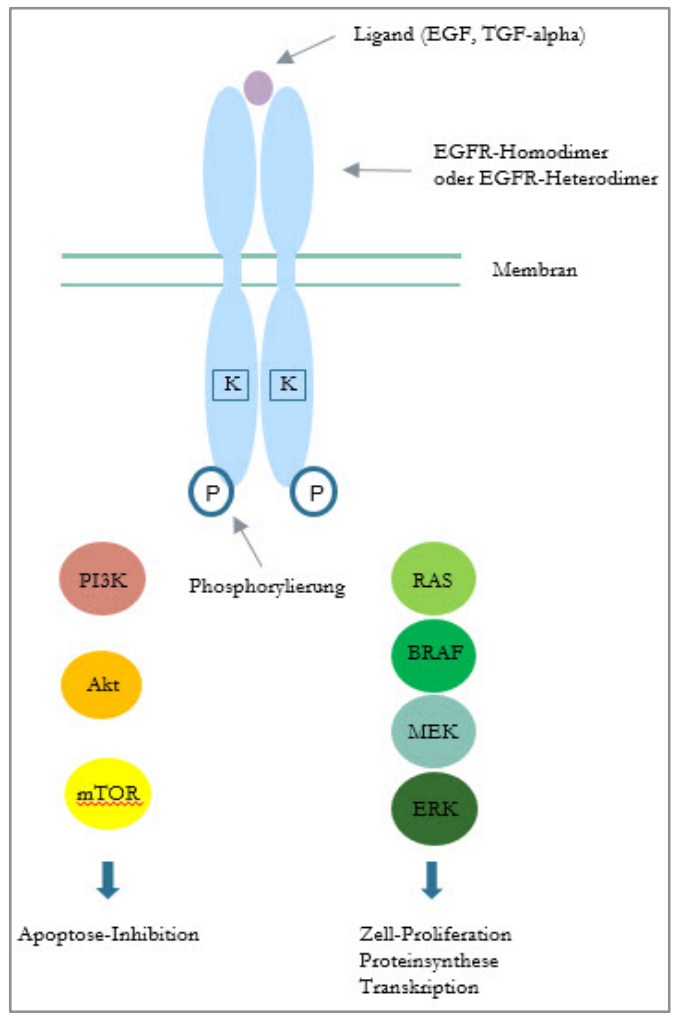

Abbildung 3: Schematische Abbildung des EGFR-Signalwegs. Die Ligandenbindung führt zur Induktion verschiedener Signalwege.

Die Ligandenbindung (EGF, TGF-alpha) führt zur Homo- oder Heterodimerisierung (Abbildung 3) und weiter zur Aktivierung der Kinasedomäne, woraufhin Signalwege in der Zelle induziert werden.

Aktivierende Mutationen von EGFR sind unter anderem beim pulmonalen Adenokarzinom beschrieben (Nicholson et al. 2001) und überwiegend bei Nichtrauchern und papillären Adenokarzinomen von asiatischen Frauen zu beobachten (The Cancer Genome Atlas Research Network 2014). Die Mutationsrate wird mit 15\% beschrieben (Keedy et al. 2011).

Die aktivierte EGFR-Mutation führt zum ungehemmten Zellwachstum, zur Angiogenese und Metastasierung (Ciardiello et al. 2004). Das gezielte Screening der Patienten mit einem EGFR-mutierten Adenokarzinom der Lunge kann dazu beitragen, die Prognose durch Gabe von Tyrosinkinase-Inhibitoren (TKI) wie z.B. Geftinib im Sinne einer „molekularzielgerichteten Therapie“ zu verbessern (Lynch et al. 2004). Einhergehend mit diesen Erkenntnissen über die molekulare Pathologie des Adenokarzinoms hat die Diagnostik onkogener Mutationen an klinischer Bedeutung gewonnen. Die häufigsten Mutationen des 
EGFR sind Punktmutationen des Exons 21 und Deletionen des Exons 19, die zur ungehemmten Aktivierung der Tyrosinkinase führen (Pao et al. 2004).

Die Erkenntnis über die Mutation in der Tyrosinkinasedomäne von EGFR führte zur Entwicklung der Therapie mit Tyrosinkinaseinhinitoren wie Gefitinib und Erlotinib. Klinische Studien zeigten, dass Patienten mit einem EGFR-mutierten Adenokarzinom der Lunge ein längeres Überleben von bis zu 8,5 Monaten progressionsfreiem Intervall und ein medianes Gesamtüberleben von bis $\mathrm{zu}$ 30,5 Monaten durch die Therapie mit Tyrosinkinaseinhibitoren zeigten. Dem gegenüber konnte durch Chemotherapie lediglich ein medianes Überleben von 23,6 Monaten erreicht werden (Mok et al. 2009; Maemondo et al. 2010; Fukuoka et al. 2011; Zhou et al. 2011; Han et al. 2012; Rosell et al. 2012; Wu et al. 2015). Patienten ohne die Mutation profitierten von der Chemotherapie (Mok et al. 2009). Diagnostiziert wird die EGFR-Mutation durch die Isolation der Tumorzellen und der anschließenden Isolation der DNA und Amplifikation interessierender Genregionen mittels Polymerase-Kettenreaktion (PCR), wodurch die Sequenzierung der Basenabfolge erfolgen kann.

\subsection{Tumorheterogenität als diagnostische Herausforderung}

Die Mutationsanalyse von Gewebeproben von pulmonalen Adenokarzinomen ist herausfordernd. Ein relevanter Faktor für die Diagnostik und Therapie der Tumorerkrankungen ist die Heterogenität des Wachstums von Tumorgewebe. Tumorzellen sind eingebettet in ein dynamisches und komplexes System aus Zellen und Geweben, die wechselseitig interagieren. Es handelt sich um eine Mischung aus verschiedenen zellulären Komponenten mit Tumorzellen, inflammatorischen Zellen (Makrophagen, Monozyten, dendritische Zellen, lymphatische Zellen), Fibroblasten, Gefäßen, der strukturgebenden Extrazellulärmatrix und der in ihr gelösten Faktoren (Chemokine, Zytokine) (Wang et al. 2017). Diese Einheit beschreibt das Tumormikromilieu. Die Wechselwirkungen zwischen Tumorzellen und ihrem umgebenden Milieu spielen eine wichtige Rolle für das Wachstum und die invasive Ausbreitung sowie Metastasierung eines malignen Tumors. Genexpressionsprofile von Tumorzellen und der Zellen verschiedener angrenzender Gewebe helfen, die Interaktion mit den umgebenden Zellen zu verstehen und so die molekularen Mechanismen der Invasion von Tumorzellen zu verdeutlichen (Wang et al. 2017). 


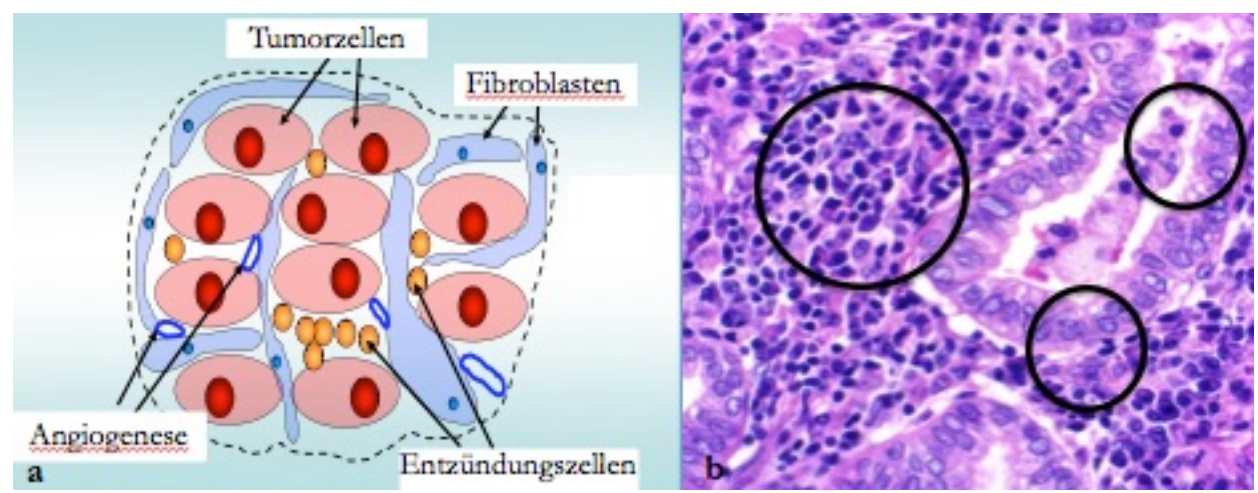

Abbildung 4: Tumormikroumgebung. a) Das heterogene Tumorgewebe mit verschiedenen Zellen schematisch dargestellt, modifiziert nach Tangrea et al. 2004. b) Pulmonales Adenokarzinom (HE, x400). Der Übergang der Tumordrüsen zum umliegenden Stroma ist mit Kreisen markiert.

Weiter stellt die Tumorheterogenität ein Problem in der Routinediagnostik dar, denn die Tumorzellen sind eingebettet in ihre heterogene Umgebung und so bieten die einzelnen kleinen Gewebeproben oft nur einen geringen Tumorzellgehalt. Bei der molekularen Analyse würde die interessierende Veränderung z.B. die EGFR-Mutation, aufgrund der geringen Tumorzellmenge durch die unveränderte DNA der umgebenden Zellen „verdünnt“, so dass falsch-negative Ergebnisse resultieren können.

Die Herausforderung besteht also darin, aus heterogenen Tumorgeweben ein möglichst homogenes Ausgangsmaterial zu erhalten, hierfür sind Mikrodissektionstechniken erforderlich.

Die Mikrodissektion stellt eine wichtige Methode dar, um Zellmaterial bei geringer Ausgangsmenge aus heterogenem Tumorgewebe anzureichern.

Eine dieser Mikrodissektionstechniken ist die Laser-Capture-Mikrodissektion (EmmertBuck et al. 1996).

\subsection{Laser-Capture-Mikrodissektion}

In der Literatur sind zahlreiche Mikrodissektionstechniken beschrieben, die sich teilweise stark voneinander unterscheiden. Die Laser-Capture-Mikrodissektion (LCM) ist eine lasergestützte Mikrodissektionstechnik, die in den 1990er Jahren an den National Institutes of Health, USA entwickelt wurde (Emmert-Buck et al. 1996) und sich zu einem wichtigen diagnostischen Werkzeug der Pathologie etabliert hat, um Tumorzellen unter direkter mikroskopischer Kontrolle aus ihrer heterogenen Umgebung zu lösen.

Mithilfe eines Lasers werden die Tumorzellen aus ihrem heterogenen Stroma isoliert und so als möglichst homogenes Ausgangsmaterial weiteren Analysen zugeführt. Die LCM 
eignet sich insbesondere für die Mikrodissektion kleiner Läsionen (Emmert-Buck et al. 1996; Bonner et al. 1997; Banks et al. 1999).

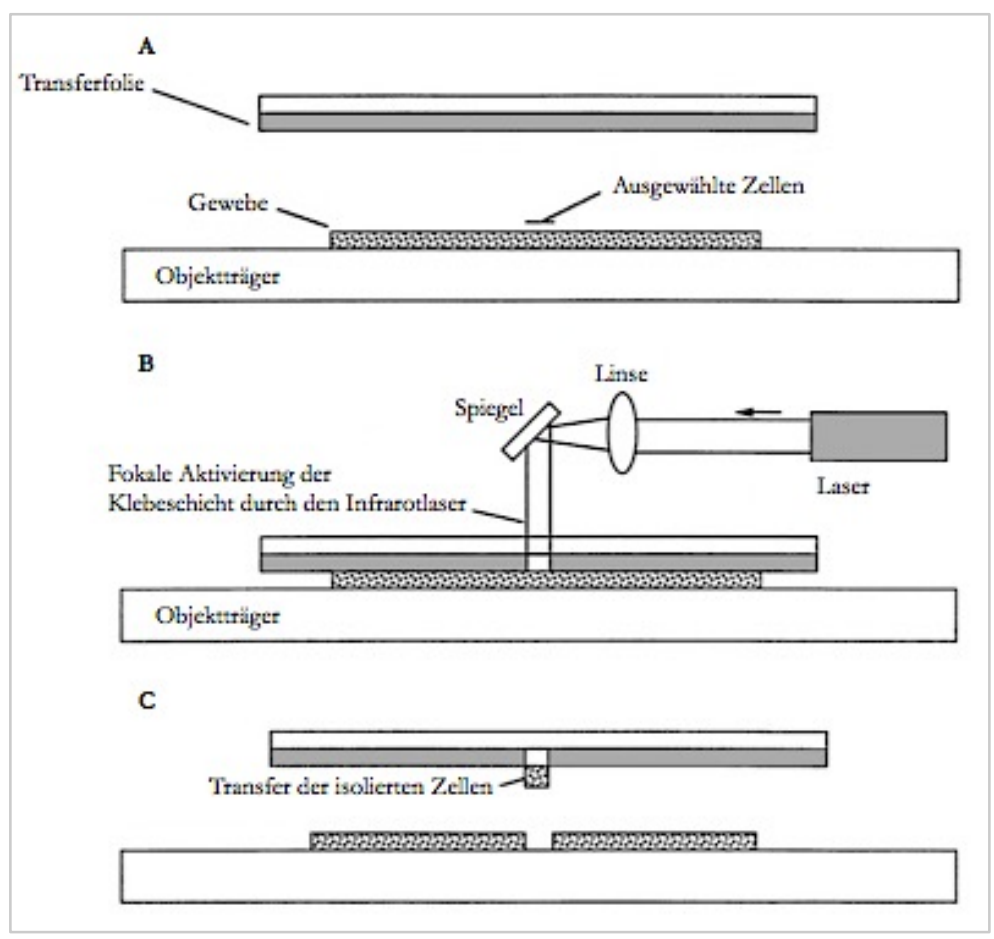

Abbildung 5: Schematische Darstellung der LCM: Eine EVA-Membran liegt dem Gewebe auf dem Objektträger auf. Die Zielzellen werden unter dem Mikroskop anvisiert (A). Ein fokussierter, zur mikroskopischen Optik koaxial verlaufender Laserstrahl aktiviert die EVA-Membran und führt, je nach verwendetem Gerät, zur fokalen Verschmelzung zwischen EVA-Membran und den ausgewählten Zellen (B). Bei Entfernung der EVA-Membran werden die isolierten Zellen transferiert (C).

Bei dieser Methode wird ein dünner Film einer Ethylen-Venyacetat-Membran (EVAMembran) auf einen Objekträger mit Gewebeschnitt aufgebracht. Durch das Mikroskop werden die Zielzellen in dem Gewebeabschnitt mittels Infrarot-Laser umfahren, was zur Verklebung des Films mit dem markierten Gewebe führt. Der Film mit den anhaftenden Zellen wird anschließend direkt den weiteren gewünschten DNA- und Proteinanalysen zugeführt (Abbildung 5).

Der Vorteil der Methode liegt in der Möglichkeit, ein definiertes Ausgangsmaterial für weitere molekulare Analysen der Zellen zu erhalten und somit die Sensitivität der Ergebnisse zu erhöhen (Emmert-Buck et al. 1996); außerdem bleibt die Zellmorphologie bei der LCM weitestgehend erhalten.

Die Methode birgt neben oben genannten Vorteilen aber auch Nachteile, vor allem die Abhängigkeit der Methode von der visuellen Genauigkeit des Untersuchers und der resultierende zeitliche Aufwand des subjektiven Identifikations- und Selektionsverfahrens. Dies setzt eine profunde Expertise in der Histologie voraus und muss durch einen 
erfahrenen Untersucher durchgeführt werden. Weiter sind die Kosten in Anschaffung und Wartung der Dissektionssysteme sehr hoch (Vi et al. 2012; Grafen et al. 2017).

\subsection{Expressionsbasierte Mikrodissektion}

Hanson et al. beschrieben 2011 eine Form der Laser-Mikrodissektion, die benutzerunabhängig und basierend auf der Expression von Antigenen durchgeführt wird. Die Methode baut auf dem zuvor von Tangrea et al. beschriebenen Originalprotokoll der expressionsbasierten Mikrodissektion auf (Tangrea et al. 2004).

Das Ziel der Methode ist, aus einem heterogenen Tumorgewebe ein definiertes Ausgangsmaterial zu erhalten. Damit sind reine Tumorzellen ohne umgebende Stromazellen gemeint, um daraus in weiterführender Diagnostik die molekulare Tumorinformation zu isolieren und zu verstehen.

Die von Hanson et al. beschriebene expressionsbasierte Mikrodissektion basiert direkt auf der tumorspezifischen Immunhistochemie mithilfe von Antikörpern. Nach ihrem Protokoll werden $5 \mu \mathrm{m}$ Gewebeschnitte angefertigt und diese immunhistochemisch mit Diaminobenzidin (DAB) gefärbt. Anschließend wird eine EVA-Folie auf das Gewebe gelegt und mit einer Walze angedrückt. Durch die hinzugeführte Energie eines handelsüblichen Epilierungs-Lasers (Arcturus PixCell II) kommt es zur Hitzeaktivierung des Chromogens der immunpositiven Tumorzellen. Dies führt zur Schmelzung der EVAFolie und zur Verklebung dieser mit den Tumorzellen. Mit einer Pinzette wird nun vorsichtig die EVA-Membran vom Gewebeschnitt entfernt, sodass nur die Tumorzellen auf der Folie haften und somit isoliert werden. Anschließend werden die transferierten Tumorzellen den gewünschten weiteren Analysen zugeführt.

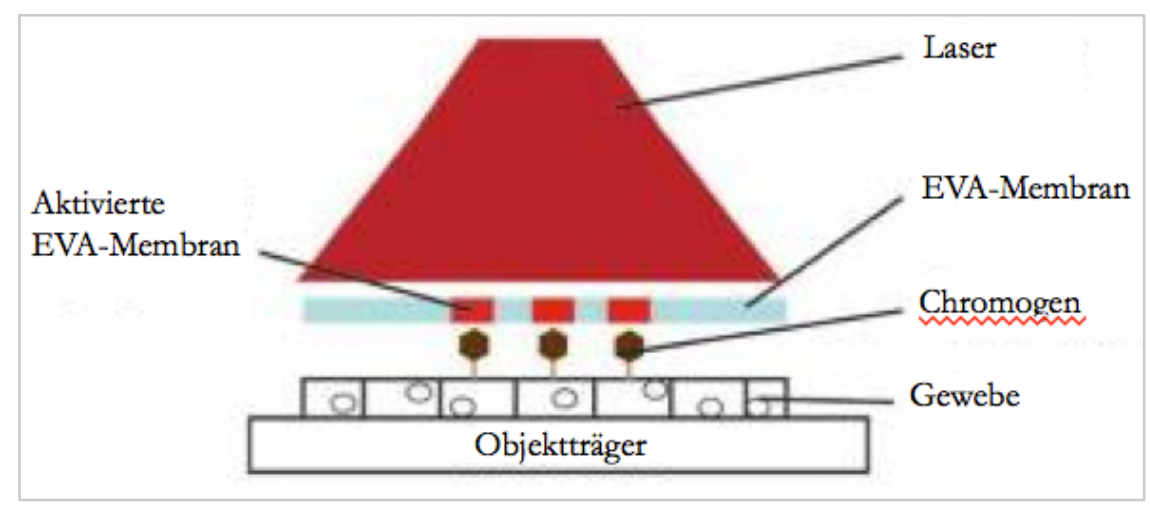

Abbildung 6: Schematisches Prinzip der xMD. Selektiv markierte Zielzellen mit der sie bedeckenden EVA-Membran. Die durch den Laser induzierte Hitze aktiviert das Chromogen, es kommt zur Bindung mit der EVA-Membran. 
Abbildung 7 zeigt Gewebe, welches immunhistochemisch gefärbt wurde. In A liegt die EVA-Folie auf. Nach Behandlung eines Feldes mit dem Laser (blau markiert) und Entfernung der EVA-Folie wird in B der erfolgte Gewebetransfer durch Abnahme der Färbeintensität sichtbar. In C ist die EVA-Folie mit anhaftenden Tumorzellen abgebildet.
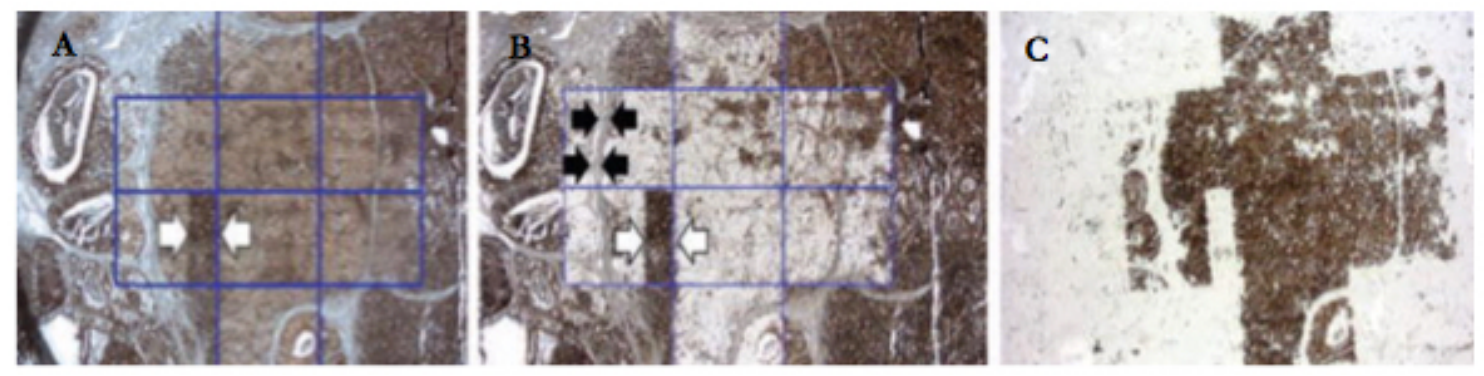

Abbildung 7: Gewebesektion immunhistochemisch markiert (braune Kernfärbung) mit aufliegender EVA-Membran. Der mit blauen Linien markierte Bereich wurde mit dem Laser behandelt (A). B zeigt den gleichen Gebeausschnitt nach der Entfernung der EVA-Membran. C zeigt die isolierten Zellen auf der entfernten EVA-Membran.

Die von Hanson et al. beschriebene Methode liefert drei entscheidende Vorteile gegenüber der konventionellen Laser-Mikrodissektion:

Das Verfahren ist unabhängig von der fachlichen Expertise der durchführenden Person, da das Selektionsverfahren durch die Antigenmarkierung erfolgt und die markierten Zellen anschließend durch die Hitze des Lasers mit der EVA-Membran verschmelzen und selektiert werden. Im Gegensatz zur konventionellen Laser-Mikrodissektion sind bei der expressionsbasierten Mikrodissektion die Selektion und das Ausschneiden der Zielzellen mit dem Mikroskop durch den Untersucher nicht nötig.

Zuletzt lassen sich die wirtschaftlichen Vorteile hervorheben. Die Kosten des Verfahrens sind deutlich geringer als bei der kommerziellen Mikrodissektion, da die Methode nicht durch einen Facharzt für Pathologie durchgeführt werden muss und der Zeitaufwand des Selektionsverfahrens deutlich geringer ist (Tangrea et al. 2004) und keine teuren Dissektionssysteme angeschafft werden müssen, da das Verfahren mit einem einfachen und handelsüblichen Haarentfernungslaser durchgeführt werden kann.

\subsection{Zielsetzung der Arbeit}

Lungenkrebs gehört sowohl beim Mann als auch bei der Frau zu den Tumorerkrankungen mit der höchsten Mortalität (International Agency for Research on Cancer 2012). In den 
letzten Jahren hat sich gezeigt, dass sich das Adenokarzinom der Lunge nicht nur histologisch, sondern auch molekular in weitere Subgruppen mit spezifischen und teilweise therapeutisch adressierbaren Veränderungen aufteilen lässt. Die Kenntnis dieser molekularen Veränderungen ist demnach relevant für die Therapie und die Prognose des Patienten. Die histologische und molekulare Aufarbeitung des Adenokarzinoms der Lunge ist jedoch herausfordernd, da meist kleine und heterogene Gewebeproben, die bronchoskopisch gewonnen werden, verschiedene diagnostische Verfahren durchlaufen. Für die molekularpathologische Analyse ist es notwendig, Tumorzellen aus einem heterogenen Stroma anzureichern, um ein möglichst homogenes Ausgangsmaterial zu erhalten. Bereits etablierte Methoden der Zellisolation, wie z. B. die LCM, haben den Nachteil, dass sie vom Untersucher und seiner Präzision sowie der histologischen Expertise abhängig und so langwierig und teuer sind. Durch die Entwicklungen der antigenexpressionsbasierten Mikrodissektion (xMD) gelang es Tangrea et al. eine benutzerunabhängige lasergestützte Mikrodissektion zu entwickeln mit der es möglich ist, ein homogenes Ausgangsmaterial und eine repräsentative Menge an Tumorzellen zu erhalten.

Ziel der vorgelegten Arbeit war es, das von Tangrea et al. entwickelte Protokoll der xMD am Institut für Pathologie der Universität Göttingen zu etablieren und zu optimieren. Weiter soll durch die DNA-Analyse und das Scannen der Objektträger die prinzipielle Durchführbarkeit von klinisch relevanten, molekularen Analysen demonstriert werden. 


\section{Material und Methoden}

\subsection{Material}

Tab. 1: Geräte

\begin{tabular}{|l|l|}
\hline Geräte & Hersteller \\
\hline Akkupipettierhilfe Akkujet & Brand Wertheim \\
\hline Akkupipettierhilfe Pipettboy & Integra, Zizers, Schweiz \\
\hline Dampfgarer Multigourmet & Braun \\
\hline Feinwaage R160P & Sartorius Göttingen \\
\hline Microtom, SM 2000R & Leicra Microsystems \\
\hline Mikroskop Axiolab & Zeiss, Göttingen \\
\hline Panoramic P250 Slide Scanner & 3D Histech, Budapest, Ungarn \\
\hline pH-Meter & Schott Instruments, Mainz \\
\hline Probenroller & ASID BONZ, Herrenberg \\
\hline SDL-15 Lasersystem & Biotechnique Avance \\
\hline Wasserbad & Heraeus, Hanau \\
\hline Wärmeschrank & Memmert \\
\hline Wärmeplatte & Leica Biosystems \\
\hline
\end{tabular}

Tab. 2: Computersoftware

\begin{tabular}{|l|l|}
\hline Software & Verwendung \\
\hline $\begin{array}{l}\text { Image J Version 1.48, NIH Bethesda, } \\
\text { Maryland }\end{array}$ & Auswertung der Bilder der xMD \\
\hline
\end{tabular}


Tab. 3: Materialien

\begin{tabular}{|l|l|}
\hline Material & Hersteller \\
\hline Deckgläschen & Menzel Braunschweig \\
\hline Mikrotom Klingen & pfm medical AG, Köln \\
\hline Objektträger Süssifrost weiss & Menzel Gläser, Gerhard Menzel GmbH \\
\hline Objektträger Superfrost & Menzel Gläser, Gerhard Menzel GmbH \\
\hline Objektträger Superfrost Plus & Menzel Gläser, Gerhard Menzel GmbH \\
\hline Pinsel & Faber-Castell, Stein \\
\hline Pinzette Dumont & Roth, Karlsruhe \\
\hline Pipetten (1, 5, 20, 100, 1000 $\mu l)$ & Eppendorf, Hamburg \\
\hline Ethylen-Venyl-Acetat-Polymerfolie & 3 M Deutschland GmbH. Neuss \\
\hline Sealing Roller, PCR Accessories, MSR0001 & Bio Rad Laboratories, Inc., München \\
\hline Shandon Coverplate & Thermo Scientific Braunschweig \\
\hline Verschlussröhrchen (1,5ml) & Eppendorf, Hamburg \\
\hline
\end{tabular}

Tab. 4: Chemikalien und Kits

\begin{tabular}{|l|l|}
\hline Lösung & Hersteller \\
\hline Antibody Diluent & Thermo Fischer Scientific \\
\hline Albumin Fraktion V (BSA) & Merck, Darmstadt \\
\hline Citronensäure-Monohydrat & Merck, Darmstadt \\
\hline $\begin{array}{l}\text { Dako REAL } \\
\text { Phosphatase/RED/ Dabbit/Mouse) }\end{array}$ & Denmark A/S, Glostrup \\
\hline Ethanol & Roth, Karlsruhe \\
\hline Tris-(hydroximethyl)-aminomethan (Tris) & Roth, Karlsruhe \\
\hline Tween 20 & Roth, Karlsruhe \\
\hline
\end{tabular}




\begin{tabular}{|l|l|}
\hline Lösung & Hersteller \\
\hline Vector Black Substrate Kit, SK-5200 & Vector Laboratories, Inc. Burlingame CA \\
\hline Xylol & Roth, Karlsruhe \\
\hline
\end{tabular}

\subsubsection{Puffer und Medien}

Sofern nicht anders angegeben wurden alle Puffer und Medien in doppelt deionisiertem Wasser (ddH2O) angesetzt. Der Citratpuffer wurde bei $100^{\circ} \mathrm{C}$ hitzeinaktiviert und im Kühlschrank gelagert. Alle Puffer und Medien wurden, wenn nicht anders angegeben, bei Raumtemperatur gelagert.

Tab. 5: Puffer und Medien

\begin{tabular}{|c|c|}
\hline Puffer und Medien & Lösungen \\
\hline Blockpuffer & $5 \% \mathrm{BSA}$ in TBS-T \\
\hline Citratpuffer Lösung A & $\begin{array}{l}21 \mathrm{~g} \text { Citronensäure-Monohydrat/1000 } \mathrm{ml} \\
\mathrm{ddH} 2 \mathrm{O}\end{array}$ \\
\hline Citratpuffer Lösung B & $\begin{array}{l}29,4 \mathrm{~g} \text { tri-Natriumcitrat-Dihydrat } / 1000 \mathrm{ml} \\
\mathrm{ddH} 2 \mathrm{O}\end{array}$ \\
\hline Citratpuffer (pH6) & 1,8 \% Lösung A, 8,2\% Lösung B in ddH2O \\
\hline HCL & 0.2 molar in ddH $2 \mathrm{O}$ \\
\hline TBS-T & $\begin{array}{l}10 \mathrm{mM} \text { Tris } / \mathrm{HCl} \mathrm{pH} \mathrm{8,0;100} \mathrm{mM} \mathrm{NaCl} \text {; } \\
0,1 \%(\mathrm{v} / \mathrm{v}) \text { Tween-20 }\end{array}$ \\
\hline Trypsin/EDTA-Lösung & $\begin{array}{l}\text { PBS; } 0,05 \%(\mathrm{w} / \mathrm{v}) \text { Trypsin; } 0,02 \%(\mathrm{w} / \mathrm{v}) \\
\text { EDTA, } 4^{\circ} \mathrm{C}\end{array}$ \\
\hline
\end{tabular}

\subsubsection{Antikörper}

In dieser Arbeit wurde der Anti-Cyrokeratin 7 Antikörper verwendet. Der Antikörper wurde für die immunhistochemischen Färbungen in TBS-T mit 5\% BSA verwendet. 
Tab. 6: Antikörper

\begin{tabular}{|l|l|l|l|}
\hline Antikörper & Spezies & Hersteller & Anwendung/Verdünnung \\
\hline Anti-Cytokeratin 7 & Maus & Dako Real & WB 1:50 \\
\hline
\end{tabular}

\subsubsection{Gewebe}

Die in dieser Arbeit verwendeten humanen Gewebeproben von Adenokarzinomen der Lunge stammen von therapeutisch indizierten, operativen Lob- und Pneumonektomien, die in der Klinik für Thorax-, Herz- und Gefäßchirurgie der Universitätsmedizin Göttingen durchgeführt wurden. Die Gewebeproben wurden nach Entnahme in 4\% gepuffertem Formalin fixiert und in dem Institut für Pathologie der Universitätsmedizin Göttingen für die histopathologische Diagnostik aufgearbeitet. Es wurden die für die Befundung nötigen Hämatoxylin- / Eosinfärbungen sowie immunhistochemische Färbungen angefertigt und die nötigen molekularpathologischen Untersuchungen, speziell die EGFRMutationsanalyse durchgeführt.

Die Verwendung der Gewebeproben erfolgte nach Maßgabe der von der Ethikkommission der Universitätsmedizin Göttingen bewilligten Ethikanträge 1-2-08 und DOK_169_2015. Die Gewebeproben wurden erst nach Abschluss der histopathologischen Diagnostik verwendet und es wurde sichergestellt, dass stets genügend Material für eventuelle weitere pathologische Untersuchungen verbleibt. Die Patienten wurden über die Verwendung der Gewebeproben aufgeklärt und haben ihre schriftliche Einwilligung dazu gegeben. Für diese Arbeit wurden Gewebeproben von Adenokarzinomen der Lunge mit einer aktivierenden EGFR-Mutation ausgewählt. 


\subsection{Methoden}

\subsubsection{Probenvorbereitungen und immunhistochemische Färbungen}

An einem Microtom wurden $10 \mu \mathrm{m}$ Gewebeschnitte gefertigt und auf Objektträger aufgetragen. Diese wurden anschließend 24 Stunden in einem Wärmeschrank bei $37,5^{\circ} \mathrm{C}$ getrocknet. Zur Vorbereitung der immunhistochemischen Färbung wurden die Paraffinschnitte zunächst 15 Minuten in Xylol und einer absteigenden Alkoholreihe von je drei mal drei Minuten 100\%, zwei mal drei Minuten 96\% und zwei mal drei Minuten 75\% Ethanol entparaffiniert und in destilliertes Wasser überführt, um sie zu hydratisieren. Anschließend wurden sie 40 Minuten in Citratpuffer bei $\mathrm{pH} 6$ gekocht, was zur hitzeinduzierten Antigendemaskierung führte. Danach wurden die Schnitte zehn Minuten in einem Eiswasserbad gekühlt. Um Lufteinschlüsse und die Austrocknung zu verhindern, wurden die Objektträger unter Wasser auf die Färbeschiene gebracht. Die Schnitte standen dabei in einem Winkel von $75^{\circ}$ zur Ablagefläche, wodurch die anschließend von oben aufgetragenen Reagenzien den gesamten Schnitt benetzten.

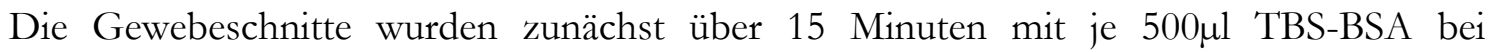
Raumtemperatur geblockt, um die Hintergrundfärbung endogener Immunglobuline zu verhindern. Der gegen humanes Cytokeratin 7 (CK7) gerichtete Primärantikörper, wurde anschließend mit je $150 \mu \mathrm{l}$ auf das Gewebe aufgetragen und 60 Minuten bei Raumtemperatur inkubiert. Anschließend wurde der Gewebeschnitt mit 500 $\mu$ l TBS-Tween je drei mal fünf Minuten gewaschen. Es folgte die Behandlung mit dem Ready-To-Use-Kit Dako REAL Detection System (Alkalin Phosphatase/RED/Rabbit/Mouse). Der Sekundärantikörper wurde mit vier Tropfen pro Objektträger aufgetragen und für 30 Minuten inkubiert. Nach einem weiteren Waschschritt von je drei mal fünf Minuten mit $500 \mu \mathrm{l}$ TBS-Tween wurden die Gewebeschnitte mit vier Tropfen von dem an den Antikörper gekoppeltem Enzym inkubiert. Nach einem weiteren Waschschritt von drei mal

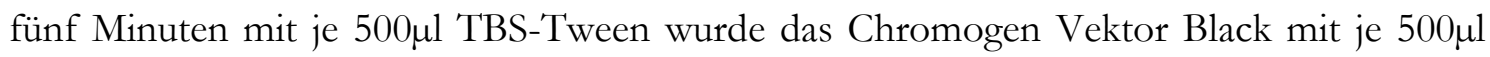
auf die Gewebeschnitte pipettiert. Dieses wurde unmittelbar zuvor aus $1 \mathrm{ml}$ 0,5 M Tris$\mathrm{HCl}(\mathrm{pH}$ 9,5) und $4 \mathrm{ml}$ ddH2O, $5 \mu$ Tween und mit je sechs Tropfen (dreifache Konzentration) aus Reagenz 1, 2 und 3 des Kits (Vektor Laboratories, Burlingame, CA) hergestellt. Das Chromogen inkubierte 30 Minuten in Dunkelheit und die Reaktion wurde anschließend mit destilliertem Wasser beendet. Es folgte die Entwässerung der Gewebeschnitte in einer aufsteigenden Ethanol-Reihe in je ein mal zwei Minuten 75\%, ein mal zwei 96\% und zwei mal fünf Minuten 100\% Ethanol und anschließend zwei Minuten in Xylol. Abschließend wurden die Gewebeschnitte bei Raumtemperatur getrocknet. 


\subsubsection{Optimierte xMD}

Eine Objekträger-Wärmeplatte wurde auf $78^{\circ} \mathrm{C}$ erhitzt und die gefärbten Gewebeschnitte fünf Minuten erwärmt. Anschließend wurde die EVA-Folie mit 19\% Vinyl-Acetat Anteil und einer Dicke von $76 \mu \mathrm{m}$ (CoTran 9715, 3M, St. Paul, MN) auf den Gewebeschnitt gelegt und mit einer Walze angedrückt, bis die Folie dem Gewebe vollständig luftdicht auflag.

Das gesamte histologische Feld wurde nun mit dem Laser (Type SDL-15, Biotechnique Avance, United Kingdom) auf Stufe 2 für die Pulsfrequenz und Stufe 3 für die LaserIntensität bestrahlt. Dabei wurden stets die Laserschutz-Richtlinien eingehalten (Schutzbrille, Latexhandschuhe und Laborkittel) und die Arbeit wurde zu zweit durchgeführt.

Der Laser wurde in einem Winkel von $90^{\circ}$ und in einem Abstand von $1 \mathrm{~cm}$ über dem Gewebe gehalten und mit etwa 1.500 Laserpulsen bestrahlt. Währenddessen konnte der Erfolg der xMD durch ein dunkleres Erscheinungsbild auf der EVA-Folie beobachtet werden, was für die laserinduzierte Verschmelzung des Chromogens auf den Tumorzellen und der EVA-Folie sprach. Nach ein bis zwei Minuten Abkühlung der Gewebeschnitte bei Raumtemperatur wurde die EVA-Folie vorsichtig mit einer Pinzette abgelöst, auf der abgezogenen EVA-Membran zeigten sich die transferierten Tumorzellen.

\subsubsection{Slide-Scanning und Bildanalyse}

Das Slide Scanning und die Bildanalyse wurden in dem Institut für Pathologie der Universitätsklinik Köln unter der Leitung von Prof. Dr. Reinhard Büttner von Dr. Andreas Scheel durchgeführt.

Die Analyse von Sensitivität und Spezifität der xMD erfolgte durch das Scannen der histologischen Schnitte vor und nach der Mikrodissektion und dem anschliessenden Vergleich der Farbintensität.

Das Scannen der histologischen Schnitte wurde mit einem Panoramic P250 Slide Scanner (3DHistech, Budapest, Ungarn) in einer Auflösung von 4,5 $\mu \mathrm{m} /$ Pixel durchgeführt und die digitale Bildanalyse erfolgte mit dem Programm ImageJ version 1.48 (National Institutes of Health, USA). Die Gewebeschnitte wurden vor und nach der xMD analysiert und die Intensitätsunterschiede miteinander verglichen. Dazu wurden die Gewebeschnitte vor der xMD mit dem Slidescanner gescannt und mit Farbüberlagerungen, die eine Abnahme der Farbintensität anzeigten, also des übertragenen Gewebes, zusammengeführt und die Intensitätsunterschiede kalkuliert. 
Die Streudiagramme der Intensitätsunterschiede wurden mit "R" Version 3.2.2 (www.rproject.org) berechnet. Die Färbeintensitäten wurden als 8 bit Graustufenwerte $\left(2^{8}=0-255\right.$; $0 \hat{=}$ white, $255 \hat{=}$ black) oder als relative Färbeintensität (0-1) dargestellt.

\subsubsection{Isolation von der EVA-Membran und Analyse der DNA-Qualität}

Die DNA-Analyse der isolierten Zellen wurde in Kooperation mit von Prof. Dr. med. Ekkehard Schütz und Dr. Julia Beck durchgeführt.

Die DNA der durch die xMD isolierten und an der EVA-Membran haftenden Tumorzellen wurde neben dem auf dem Objektträger verbliebenen Geweberest und einem unbehandelten Kontrollschnitt von Zellen des Adenokarzinoms der Lunge mittels GeneRead DNA FFPE Kit (Qiagen, Hilden, Germany) nach dem Protokoll des Herstellers in modifizierter Form extrahiert. Da das Gewebe in der Vorbehandlung entparaffiniert wurde, entfiel der Entparaffinierungsschritt, die Proteinkinase-K-Enzym-Lösung wurde in doppelter Menge verwendet und die Verdauungsphase auf zwei Stunden erhöht. Die Konzentration der DNA wurde mittels Digital-PCR und mithilfe des Taqman Assays bestimmt. Das Verfahren wurde auf die Region von 91 bp auf Chromosom 5:1370219013702281 ausgerichtet. Die Nukleotidsequenzen der Primer lauteten: FWD:TGCTTCTGACTTTCTCCCTGA und REV:ACACTGCTGCTGCTGATGAC.

Die interne Sonde wurde mit dem Farbstoff HEX markiert und durch den Blackhole Quencher 1 wieder gelöscht. Die Reaktionen wurden in 1x ddPCR Super-Mix für Proben (Bio-Rad, Hercules, USA) in ein $20 \mu \mathrm{L}$ Gefäß mit $250 \mathrm{nM}$ der Probe und $900 \mathrm{nM}$ von jedem Primer durchgeführt. Die EGFR E746-A750del Mutation und das korrespondierende Wild-Typ Allel wurden mit Allel spezifischen Primern (EGFRdelA746A750.FWD: 5-AATTCCCGTCGCTATCAAAAC-3; EGFR_wildtype.FWD: 5CCGTCGCTATCAAGGAATTAAG-3), mit einem universellen Gegenprimer (EGFR.REV: 5-CCACACAGCAAAGCAGAAA-3) und einer Universalsonde (EGFR.Probe: FAM-5-CCAACAAGGAAATCCTCGATGT-3-BHQ1) detektiert. Die Reaktionen wurden wie oben beschrieben durchgeführt, wobei die Primerkonzentrationen auf $225 \mathrm{nM}$ je Primer gesenkt wurden. 


\section{Ergebnisse}

Die expressionsbasierte Mikrodissektion (xMD) beruht auf der zellspezifischen Immunhistochemie, der Absorption der Laserenergie durch die resultierende Färbung der markierten Zellen und der durch den Laser erzeugten fokalen Hitze, die zur Verschmelzung des Chromogens auf den gefärbten Zellen und der das Gewebe bedeckenden EVA-Folie führt.

\subsection{Optimierung der xMD}

Wir reproduzierten das von Tangrea et al. beschriebene Protokoll der xMD an Gewebeproben des Adenokarzinoms der Lunge. Es wurden zunächst immunhistochemische Färbungen mit $\mathrm{DAB}$ in dreifacher Konzentration von Gewebeschnitten des Adenokarzinoms der Lunge angefertigt. Die Färbeintensität des Chromogens DAB in dreifacher Konzentration erzeugte einen braunen Farbniederschlag (Abbildung 8).

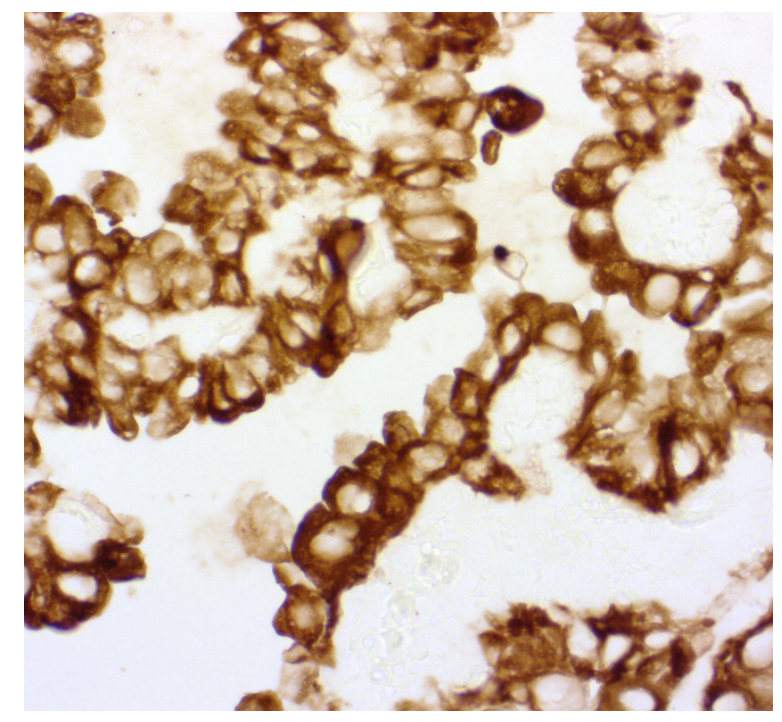

Abbildung 8: Lunge Adenokarzinom, CK7 1:50, Vergrößerung x400. DAB Konzentration x3.

Auf die gefärbten Schnitte wurde die EVA-Folie gelegt und mit einer Walze angedrückt. Durch die nun zugeführte Laserenergie, die zur fokalen Hitzeerzeugung und zur Verschmelzung des Chromogens auf der Zelle und der EVA-Folie führen soll, war die Hitzentwicklung zu gering, so dass es zu keiner Verschmelzung des Chromogens mit der EVA-Folie kam. Im Folgenden wurden deshalb die Farbintensität, die Oberflächenbeschaffenheit des Objektträgers bezüglich der Haftung des Gewebes und die 
Vorbehandlung zur Wiederherstellung der Antigenität des Gewebes zur Durchführung der expressionsbasierten Mikrodissektion am pulmonalen Adenokarzinom optimiert.

\subsubsection{Optimierung der Immunhistochemie}

Die Immunhistochemie ist ein vielfach genutztes diagnostisches Verfahren in der Pathologie. Sie ermöglicht die Visualisierung von zellulären Strukturen in histologischen Gewebeschnitten über die Bindung von Antikörpern, die gegen diese Strukturen (Antigene) gerichtet sind. Dabei bindet ein Antikörper an das passende Antigen, welches dann farblich markiert wird. In dieser Arbeit kam die Labeled-(Strept-)Avidin-Methode (LSAB) zur Anwendung, bei der man sich an der starken Affinität des hydrophilen Vitamins Biotin zu dem Glykoprotein Avidin oder Streptavidin bedient, ein aus Hühnereiweiß bestehendes Glykoprotein mit vier Bindungsstellen für Biotin. Ein mit Biotin markierter Brückenantikörper reagiert mit dem Primärantikörper und dieser lässt sich so mit dem Streptavidin-Enzymkonjugatkomplex, der an dritter Stelle aufgetragen wird, koppeln. Anschließend wird durch die chromogene Substratlösung, in dieser Arbeit Vector Black, der Primärantikörper sichtbar gemacht.

Bei der xMD wird die Energie des Lasers durch dunkel gefärbte Zellen absorbiert, es entwickelt sich daraufhin fokal Hitze, die zur Verschmelzung der Zielzellen mit der EVAMembran führt. Da sich bei den oben beschriebenen Färbungen Optimierungsbedarf zeigte, wurde mit dem Ziel die Färbeintensität zu verstärken anstelle des Chromogens DAB das Chromogen Vektor Black in der Kombination mit Anti-CK 7 als Primärantikörper an Gewebe des Adenokarzinoms der Lunge getestet. Es zeigte sich, dass Vektor Black, im Vergleich zu DAB, zu einer intensiveren Färbung der Tumorzellen führte.
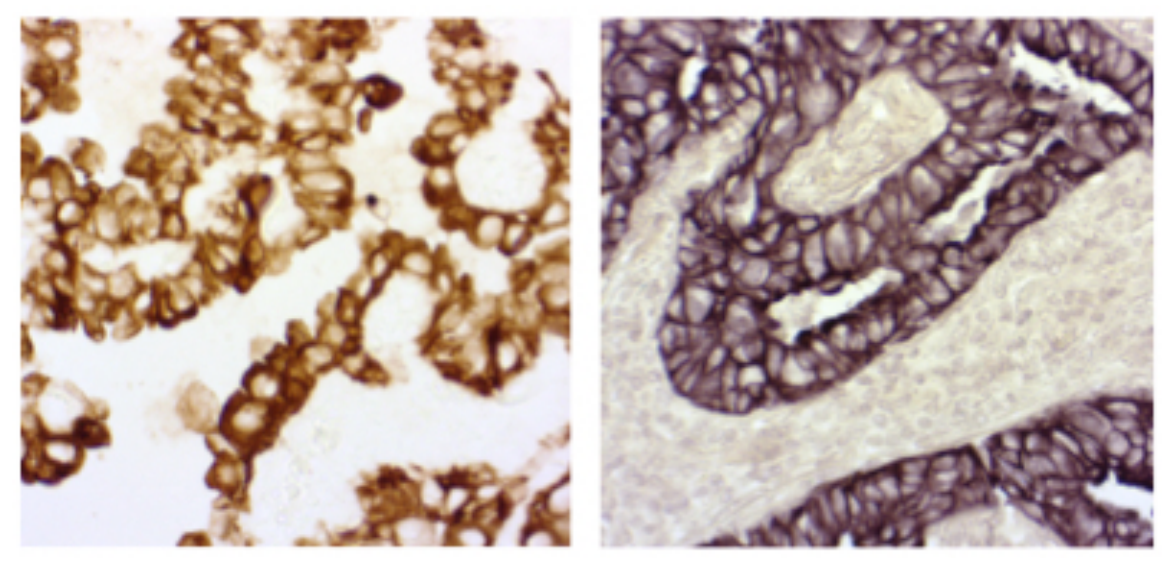

Abbildung 9: Vergleich der Chromogene. Links DAB, rechts Vektor Black, Konzentration x1.

Insbesondere bei Verdreifachung der Konzentration des Vektor Black Chromomogens (Abbildung 10) wurde eine starke, dunkle Färbung der Tumorzellen erzielt 


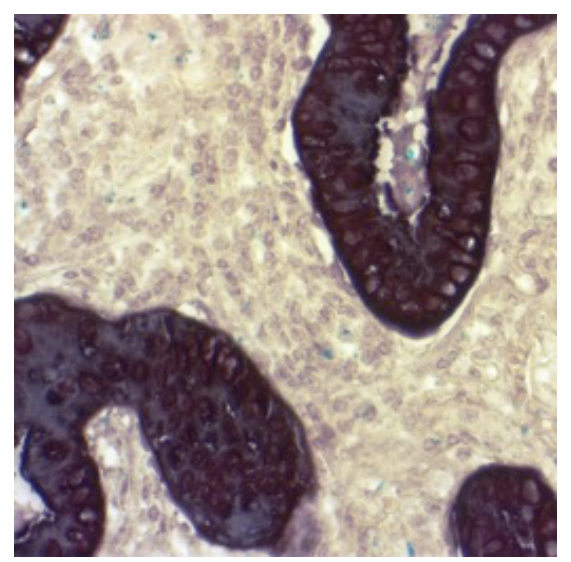

Abbildung 10: Lunge Adenokarzinom. CK7 1:50, Vektor Black, Konzentration x3, Vergrößerung x40.

\subsubsection{Vergleich von Vorbehandlung und Objektträgern}

Es wurden drei verschiedene Objektträger (OT) getestet, um die optimale Kombination von Haftung und Lösbarkeit des Gewebes am Objektträger für die Methode zu finden. Dabei wurden konventionelle Objektträger aus Glas ohne Beschichtung (Süsse Objektträger, Süsse Labortechnik, Gudensburg, Deutschland), Superfrost Objektträger aus poliertem Glas (Menzel Superfrost, Thermo Scientific, Life Technologies GmbH, Darmstadt, Deutschland) und Superfrost Plus (Menzel Superfrost Plus, Thermo Scientific, Life Technologies GmbH, Darmstadt, Deutschland), ein silanisierter Adhäsionsobjektträger, welcher durch seine permanent positive Ladung gekennzeichnet ist und einer guten Haftung des Gewebes dient miteinander verglichen. Zunächst wurden am Microtom $10 \mu \mathrm{m}$ dicke Gewebeschnitte angefertigt und auf den drei verschiedenen Objektträgern im Wärmeschrank bei $37,5^{\circ} \mathrm{C}$ getrocknet. Je eine Reihe trocknete 24 Stunden, je eine zweite Reihe trocknete 72 Stunden. Nach der anschließenden Vorbehandlung zur Wiederherstellung der Antigenität des Gewebes mit Citratpuffer oder vergleichend mit Protease $\mathrm{K}$ zeigte sich auf dem Superfrost Plus Objektträger nach 24 Stunden sowie nach 72 Stunden Trocknungszeit kein Unterschied in der Gewebehaftung. Auf dem konventionellen Objekträger löste sich das Gewebe, unabhängig von der Trocknungszeit, während der Vorbehandlung mit Citratpuffer teilweise oder vollständig ab (Abbildung 11). Nach Vorbehandlung mit Proteinase K blieb das Gewebe teilweise haften, aber das Ergebnis der anschließenden Färbung war unspezifisch. 

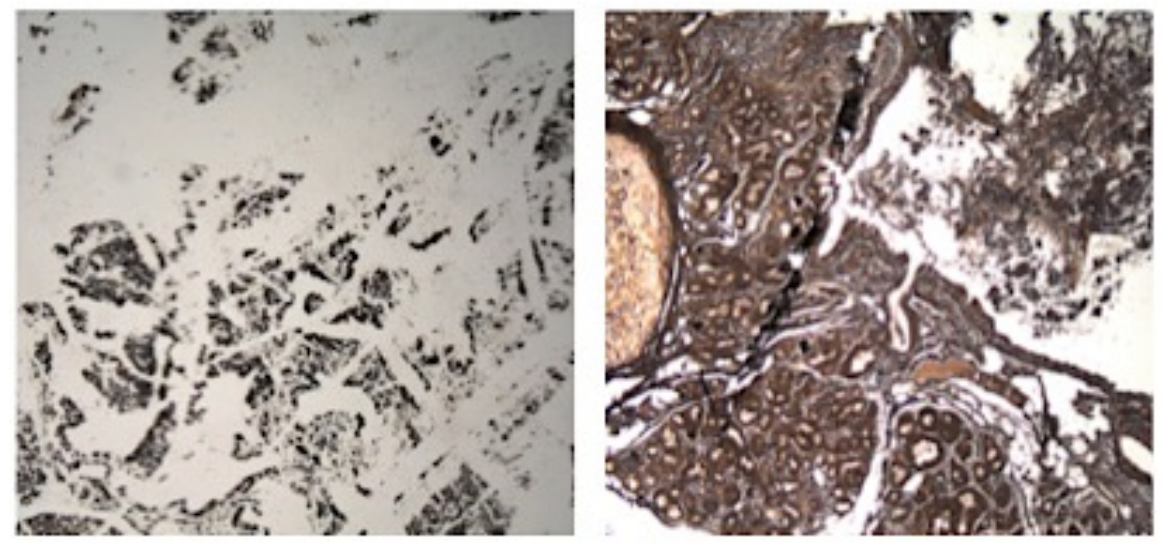

Abbildung 11: Vergleich der Objektträger nach Vorbehandlung. Adenokarzinom der Lunge, $10 \mu \mathrm{m}$. Links: Objektträger unbeschichtet, nach Vorbehandlung mit Citratpuffer und Färbung mit Vektor Black. Rechts: Objektträger unbeschichtet nach Vorbehandlung mit Proteinase K und Färbung mit Vektor Black.

Ähnlich löste sich auf dem Superfrost Objektträger teilweise Gewebe nach Vorbehandlung mit Citratpuffer und Proteinase ab, weiter war auch die Färbung unabhängig von der Vorbehandlung unspezifisch (Abbildung 12).
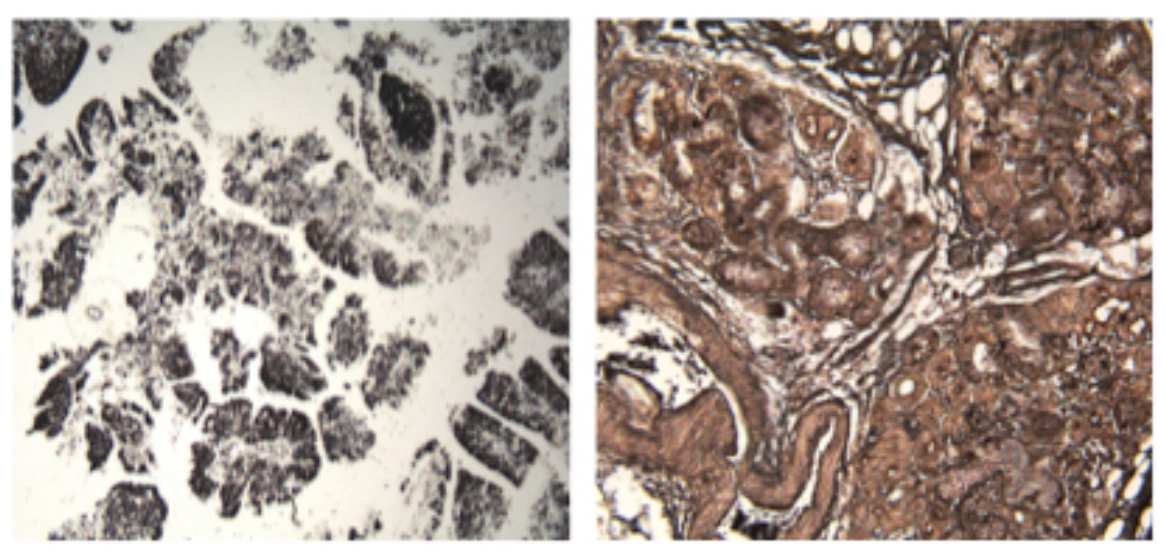

Abbildung 12: Vergleich der Objektträger nach Vorbehandlung. Adenokarzinom der Lunge $10 \mu \mathrm{m}$. Links: Objektträger Superfrost, Vorbehandlung Citratpuffer, Färbung Vektor Black. Rechts: Objektträger Superfrost, Vorbehandlung Proteinase, Färbung Vektor Black.

Auf dem Superfrost Plus OT haftete das Gewebe ohne Verlust durch die Vorbehandlung. Die anschließende Färbung mit Vektor Black war nach der Citratpuffer-Vorbehandlung spezifischer (Abbildung 13), demnach wurde folgend der Superfrost Plus OT, eine Trocknungszeit von 24 Stunden und die Vorbehandlung mit Citratpuffer für diese Arbeit etabliert. 

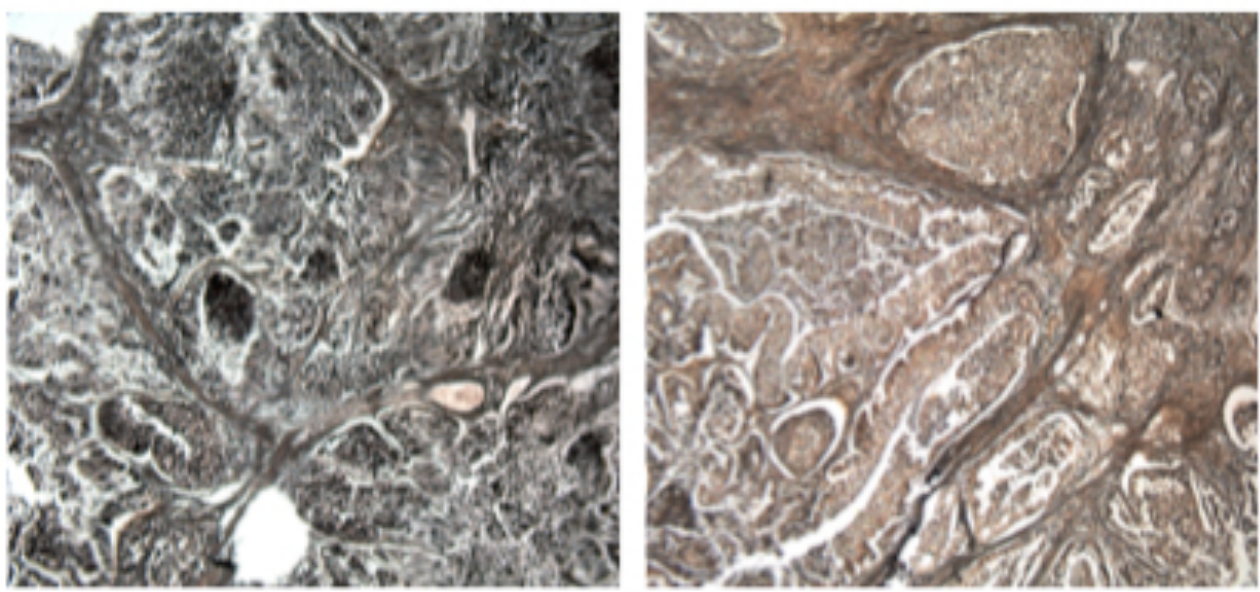

Abbildung 13: Adenokarzinom der Lunge, 10 $\mu \mathrm{m}$, OT Superfrost + . Links: Vorbehandlung mit Citratpuffer, Färbung Vektor Black. Rechts: Vorbehandlung mit Protease K, Färbung Vektor Black.

Tabelle 7 fasst die oben beschriebenen Ergebnisse vergleichend zusammen. Es wird deutlich, dass es vor allem bei Benutzung des Superfrost Plus Objektträgers zu keinem Gewebeverlust gekommen ist.

Tab. 7: Vergleich von Objektträgern. Unbeschichtet, Superfrost, Superfrost Plus. Vorbehandlung mit Citratpuffer und Protease K. + kennzeichnet eine gute Gewebehaftung nach der Vorbehandlung. +/- zeigt Gewebeverluste an. - bezeichnet den Verlust des Gewebes.

\begin{tabular}{|l|c|c|c|c|c|c|}
\hline Objektträger & \multicolumn{2}{|c|}{ Glas } & \multicolumn{2}{c|}{ Superfrost } & \multicolumn{2}{c|}{ Superfrost Plus } \\
\hline Dicke $(\mu \mathrm{m})$ & \multicolumn{2}{|c|}{10} & \multicolumn{2}{c|}{10} & \multicolumn{2}{c|}{10} \\
\hline 24h Citratpuffer & - & - & $+/-$ & $+/-$ & + & + \\
\hline 24h Protease K & - & - & $+/-$ & $+/-$ & + & + \\
\hline 72h Citratpuffer & - & - & + & + & + & + \\
\hline 72h Protease K & - & - & + & + & + & + \\
\hline
\end{tabular}

\subsubsection{Optimierung der technischen Durchführung der xMD}

Die xMD wurde an den mit Vektor Black in dreifacher Konzentration gefärbten Gewebeschnitten gemäß des Originalprotokolls durchgeführt und dabei konnten erste Erfolge erzielt werden, indem Tumorzellen auf der entfernten EVA-Membran hafteten. Die lokale, hitzeinduzierte Verschmelzung der EVA-Membran mit den Tumorzellen ließ sich weiter optimieren, indem die Gewebeschnitte konstant durch eine Wärmeplatte erhitzt 
wurden. Neben der Energie der Laserquelle, die zur fokalen Hitzeentwicklung führte, konnte die Effizienz der Mikrodissektion so erhöht und konstant gehalten werden. Abbildung 14 zeigt den technischen Aufbau der optimierten xMD und die erfolgreiche Mikrodissektion der Tumorzellen mithilfe der EVA-Membran.

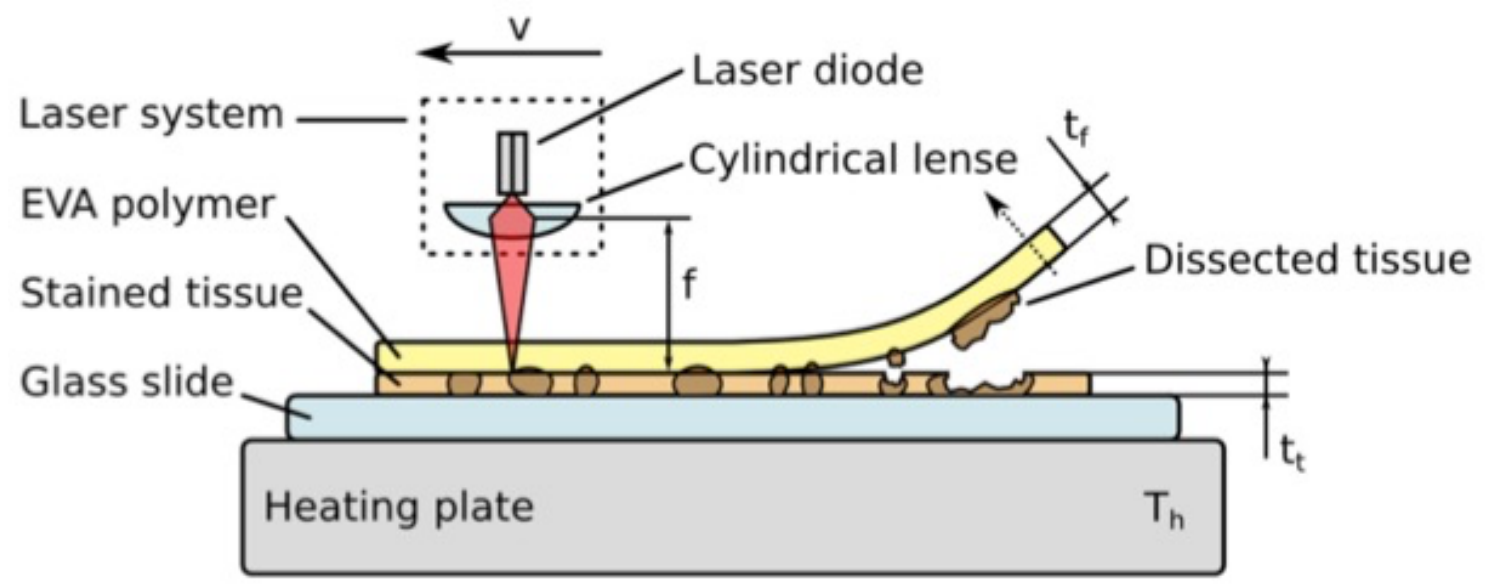

Abbildung 14: Schematische Darstellung der optimierten xMD. Immunhistochemisch behandeltes Gewebe des Adenokarzinoms der Lunge, auf einer Wärmeplatte aufliegend. Ein Lasergerät wurde für die Bestrahlung des Feldes genutzt. Auf der EVA-Membran haften die transferierten Tumorzellen.

\subsection{Vergleichende Bildanalyse von Gewebeproben vor und nach Mikrodissektion}

Das Slide-Scanning und die Bildanalyse wurden im Institut für Pathologie der Universitätsklinik Köln unter der Leitung von Prof. Dr. Reinhard Büttner von Dr. Andreas Scheel durchgeführt.

Die Verschmelzung der EVA-Folie mit dem darunterliegenden Gewebe lässt sich bei Durchführung der xMD durch eine zunehmende, dunkle, feucht wirkende Erscheinung auf der EVA-Membran beobachten. Zur Bewertung des xMD-Transfers können die Gewebeschnitte vor und nach der xMD lichtmikroskopisch untersucht werden. Mithilfe digitaler Slide-Scanner lassen sich die histologischen Schnitte in hoher Auflösung digitalisieren. Dies ermöglicht den direkten Vergleich und die Analyse der Gewebeschnitte. Um die Änderungen vor- und nach dem Transfer zu analysieren und dokumentieren, erfolgte die Digitalisierung der Gewebeschnitte. Abbildung 15 a1 und b1 zeigt eine Gewebeprobe nach der histologischen Färbung mit CK 7 und Vektor Black in dreifacher Konzentration vor der xMD.

In Abbildung $15 \mathrm{a} 2$ und b2 wird die Verringerung der Färbeintensität visualisiert, die dem übertragenen Gewebe entspricht und 15 a3 und b3 zeigt den Objektträger nach erfolgter xMD 

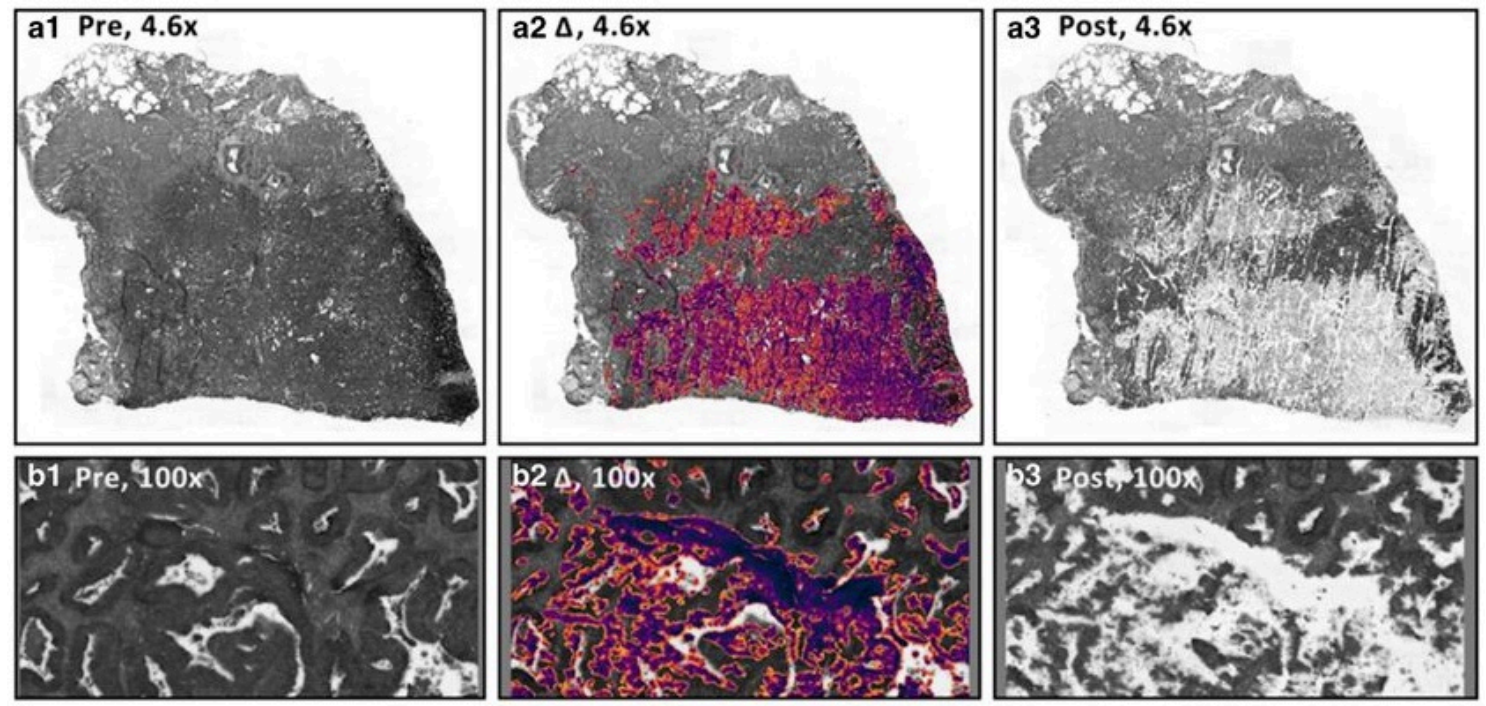

Abbildung 15: Bildanalyse von mikrodisseziertem Gewebe des Adenokarzinoms der Lunge vor und nach der xMD. Eine Adenokarzinom-Probe vor Mikrodissektion a1; vergrößertes Detail b1. Die Visualisierung der verringerten Färbungsintensität, die dem übertragenen Gewebe entspricht a2, vergrößertes Detail b2. Eine Adenokarzinom-Probe nach xMD a3, vergrößertes Detail b3.

Die Intensität jedes einzelnen Pixels vor und nach der xMD wurde in einem Streudiagramm aufgetragen, um diese zu quantifizieren. Hier wurde deutlich, dass speziell Bereiche mit hoher Farbintensität $(>100)$ vor der xMD nach der xMD eine verringerte Farbintensität (0-100) zeigten (Abbildung 16A). Die Bereiche mit mäßiger oder geringer Farbintensität zeigten in beiden Scans vergleichbare Werte. Dieser Effekt ließ sich gut durch Berechnung des Mittelwertes für jede Farbintensität beobachten (Abbildung 16B).
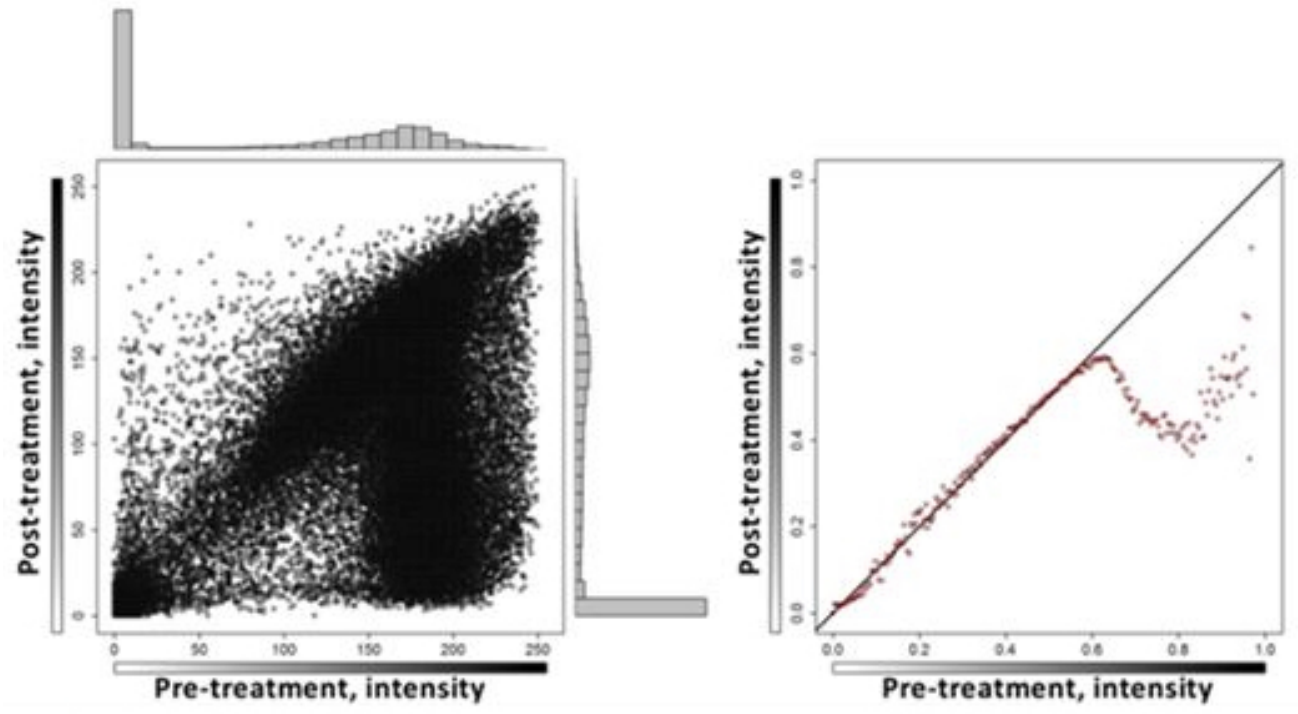

A

B

Abbildung 16: Streudiagramm der Intensität jede Pixels vor und nach der xMD. 
Mit einer Negativkontrolle konnte die Abnahme der Färbeintensität und somit der erfolgreiche Transfer der Tumorzellen geprüft werden; es wurden zwei Objektträger vor und nach der xMD miteinander verglichen, jedoch wurde der Einsatz des Lasers ausgespart. Der Vergleich der Färbeintensität vor und nach der xMD, ohne Einsatz des Lasers, zeigt keinen Unterschied in der Färbeintensität (Abbildung 17).

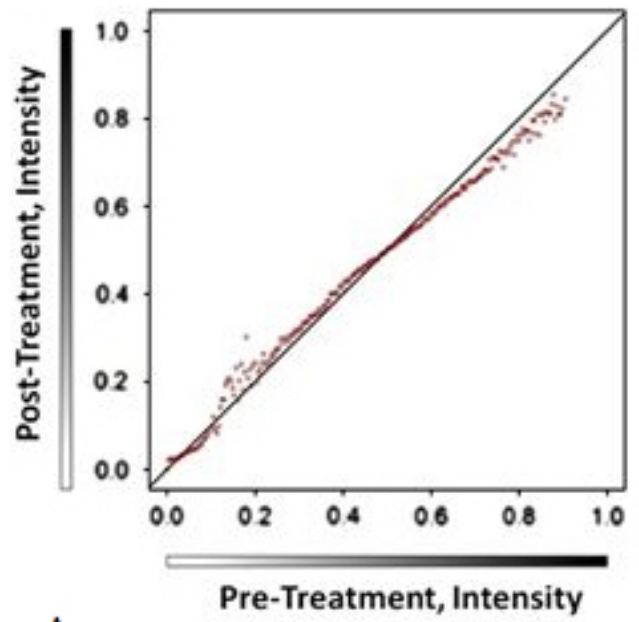

A

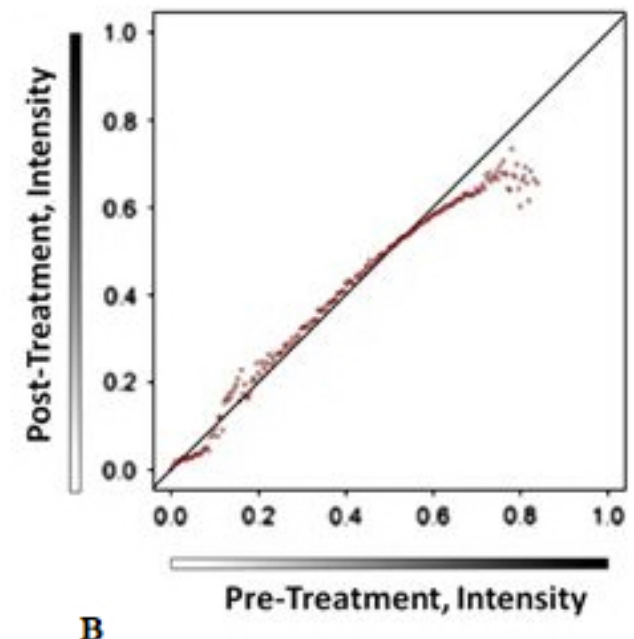

B

Abbildung 17: Simulierte Mikrodissektion von Lungenkrebsgewebe. Aufgetragen sind die Mittelwerte der Färbeintensität jedes Pixels vor und nach der Mikrodissektion ohne Anwendung des Lasers (ScheinMikrodissektion).

Zuletzt konnte die sichere Reproduzierbarkeit des optimierten xMD-Protokolls anhand der digitalen Bildanalyse durch die Messung der Färbeintensität nach der xMD an vier voneinander unabhängigen Proben gezeigt werden (Abbildung 18). Alle Proben zeigten nahezu gleiche Veränderungen nach der xMD.

\subsection{DNA-Isolation von der EVA-Membran und Analyse ihrer Qualität}

Die DNA-Analyse der isolierten Zellen wurde in Kooperation mit Prof. Dr. med. Ekkehard Schütz und Dr. Julia Beck durchgeführt.

Die Analyse der DNA erfolgte dabei durch eine quantitative Echtzeit-PCR, eine Vervielfältigungsmethode für Nukleinsäuren, die auf dem Prinzip der PolymeraseKettenreaktion beruht und so eine Vervielfältigung der zuvor gewonnenen DNA ermöglicht. Weiter ist es möglich, durch die Echtzeit-PCR zwischen homozygoten und heterozygoten Merkmalsausprägungen zu unterscheiden, was für diese Arbeit von Interesse 
war, da es sich bei der EGFR-Mutation des Adenokarzinoms der Lunge um eine heterozygote Merkmalsausprägung handelt.

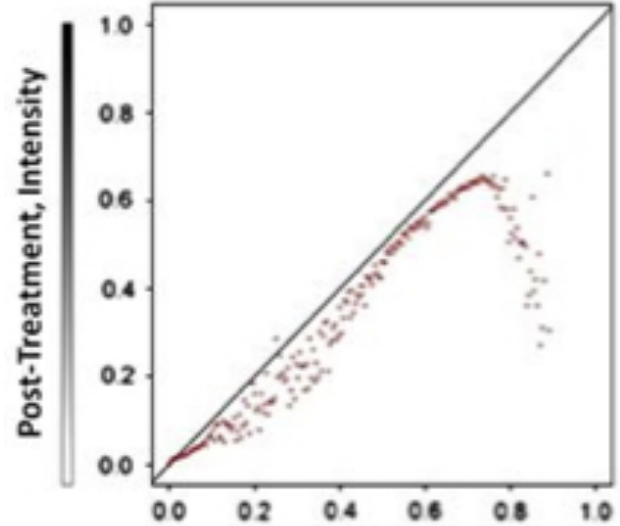

A
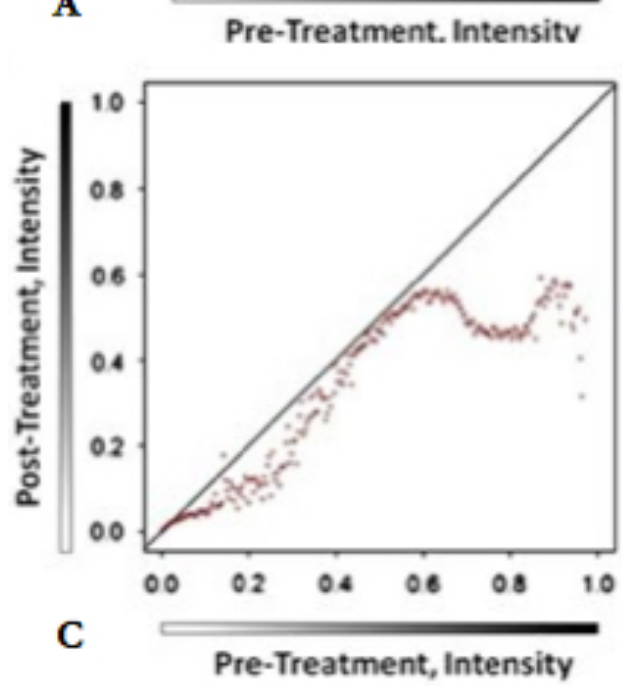

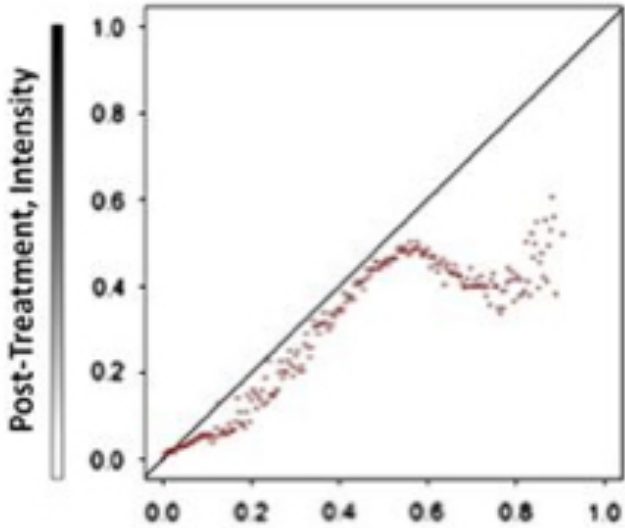

B

Pre-Treatment. Intensitv

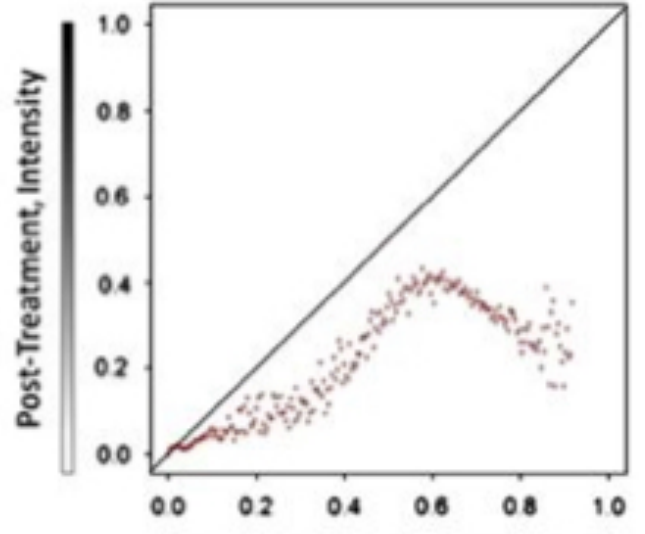

D

Pre-Treatment, Intensity

Abbildung 18: Darstellung der Reproduzierbarkeit der xMD von Lungenkrebsgewebe. Anhand von vier verschiedenen Proben des Adenokarzinoms der Lunge (A-D) wird die Reproduzierbarkeit der xMD demonstriert.

DNA aus formalin-fixiertem Gewebe ist häufig stark fragmentiert und chemisch modifiziert, was zu einem Verlust der Sensitivität der DNA führen kann (Didelot et al. 2013). Die Integrität der DNA wurde zunächst anhand einer DNA-Probe, die von der EVA-Membran isoliert wurde, mittels Kapillarelektrophorese geprüft (Abb. 20), um herauszufinden, ob die immunhistochemische Behandlung oder die nachfolgende xMD die Qualität der DNA beeinflussen. Das Ergebnis zeigte eine mediane DNA-Fragmentlänge von circa 650 Basenpaaren in den von der EVA-Membran isolierten Zellen, dies ist vergleichbar mit der DNA-Fragmentlänge von formalinfixiertem Gewebe, das keine Immunhistochemie oder xMD durchlief. 


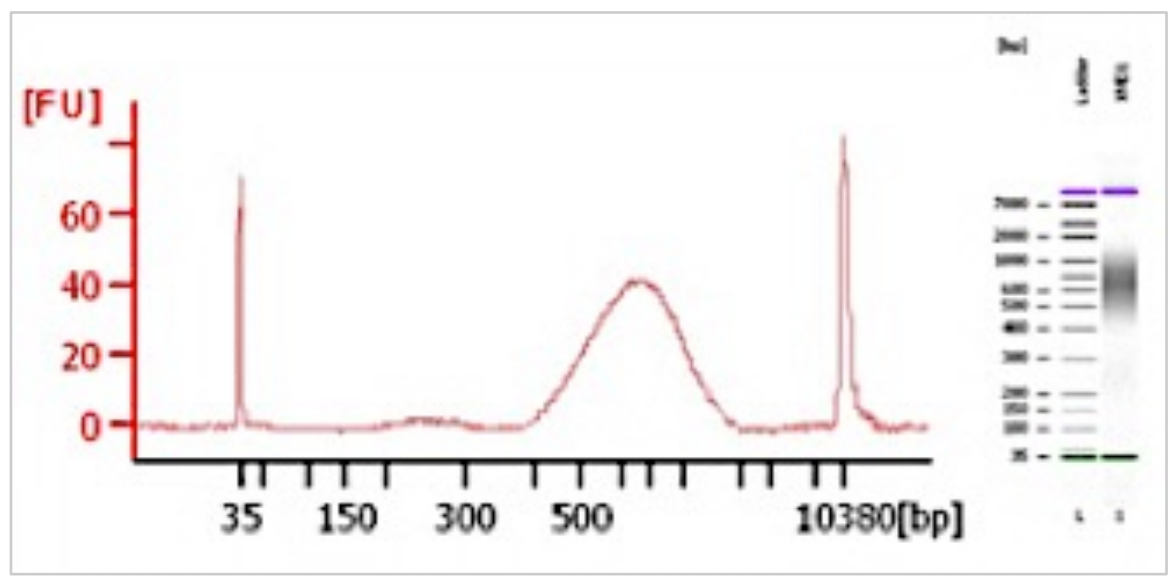

Abbildung 19: DNA-Analyse von mikrodisseziertem Lungenkrebsgewebe. Elektropherogramm (Agilent Bioanalyzer 2100) der von der EVA-Membran isolierten DNA.

Weiter wurde die amplifizierbare DNA-Menge für vier verschiedene Proben des Adenokarzinoms durch die digitale PCR quantifiziert. Es wurden je Probe die auf der EVA-Membran haftenden Zellen, der auf den Objektträgern verbleibende Rest und eine unbehandelte Kontrolle verglichen.

Tab. 8: Menge amplifizierbarer DNA per Probe. Vergleich von vier verschiedenen Proben des Adenokarzinoms der Lunge, getestet durch ein 91bp Amplikon und quantifiziert mittels digitaler PCR.

\begin{tabular}{|c|c|}
\hline Probe & Amplifizierbare extrahierte DNA (ng) \\
\hline 1-Kontrolle & 165 \\
\hline 1-Rest & 101 \\
\hline 1-EVA & 315 \\
\hline 2-Kontrolle & 750 \\
\hline 2-Rest & 1035 \\
\hline 2-EVA & 14 \\
\hline 3-Kontrolle & 64 \\
\hline 3-Rest & 75 \\
\hline 3-EVA & 14 \\
\hline 4-Kontrolle & 387 \\
\hline 4-Rest & 422 \\
\hline 4-EVA & 5 \\
\hline
\end{tabular}

Die DNA-Menge, die von der EVA-Membran isoliert wurde, war geringer als die DNAMenge, die von der nicht mikrodissezierten Kontrolle gewonnen wurde, aber ausreichend 
für die Amplifikation und Quantifizierung eines 91 Basenpaar Amplikons durch die digitale Droplet-PCR. Abbildung 20 zeigt 1-D-Plots der digitalen Droplet PCR. Es ließen sich deutlich positive (grün) und negative (schwarz) Plots darstellen.

Insbesondere bei der Analyse von FFPE-DNA werden häufig Tröpfchen mit niedrigeren Fluoreszenzamplituden gesehen, diese Tröpfchen werden üblicherweise als Regen bezeichnet. Sie enthalten vermutlich chemisch modifizierte und/oder fragmentierte Moleküle, wodurch die Amplifikationseffizienz negativ beeinflusst wird. Vergleicht man die aus den Kontrollschnitten extrahierte DNA mit der EVA-Membran und der Rest-DNA (Abbildung 20), so vermehrte sich der Grad des Regens nicht, was darauf hindeutet, dass durch die IHC und die Mikrodissektion keine weitere DNA-Schädigung verursacht wurden.
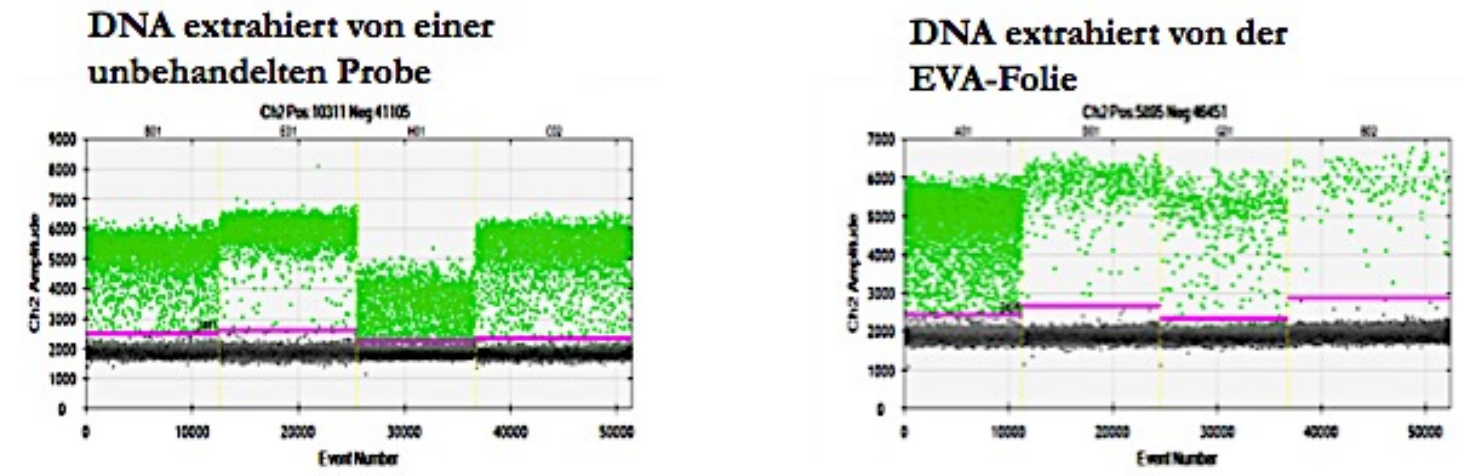

DNA extrahiert vom Rest

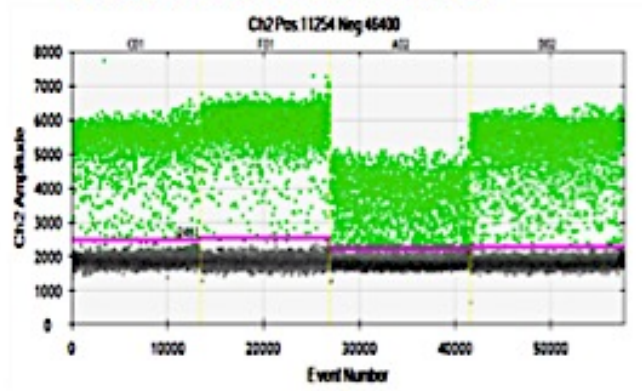

Abbildung 20: 1D Plots der Digitalen PCR des 91-BP-Amplikons zeigen die grünen positiven und die schwarzen negativen Banden der amplifizierten DANN.

Zuletzt wurden drei weitere Proben des EGFR-mutierten Adenokarzinoms zur Quantifizierung der Ratio von EGFR-Mutation und Wild-Typ-EGFR untersucht. Dazu wurden von der EVA-Membran isolierte Zellen, mit unbehandelten DNA-Proben und dem auf dem Ojektträger verbleibenden DNA-Rest mittels digitaler PCR miteinander verglichen. Abbildung 21 zeigt bei den mikrodissezierten Proben eine Erhöhung der Allelfrequenzen mit EGFR-Mutation, wohingegen sich eine Abnahme der EGFRmutierten DNA auf den Resten der Objektträger fand. 
Abbildung 21 zeigt weiter, dass die Konzentration der EGFR-mutierten DNA durch die xMD erhöht wurde. Die Anreicherung der EGFR-mutierten DNA betrug in der EVAProbe 1 89\% der Gesamt-DNA, in der unbehandelten Kontrolle betrug die Anreicherung im Vergleich nur 30\%. In der EVA-Probe 2 ließ sich sogar eine Anreicherung auf 93\% der EGFR-mutierten DNA erreichen.

\section{Digitale-PCR EGFR}

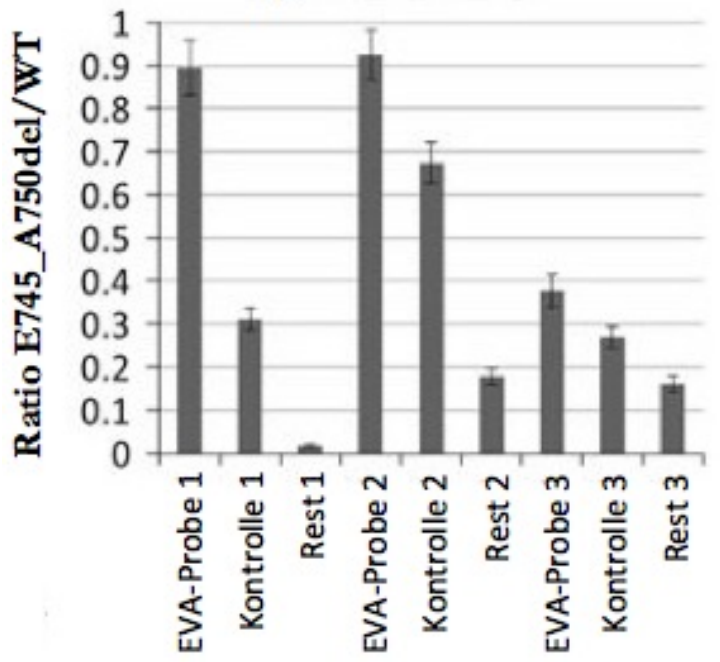

Abbildung 21: Ratio von mutierter EGFR (E746-A750del) zu wild-typ-EGFR. Isoliert von ungefärbten und nicht dissezierten Proben (Kontrolle), von der EVA-Membran nach xMD und sowie von dem nicht transferierten auf dem Objektträger verbleibendem Rest dreier verschiedener Proben des Adenokarzinoms der Lunge. 


\section{Diskussion}

Das Bronchialkarzinom ist eine der weltweit häufigsten zum Tode führenden Tumorerkrankungen (International Agency for Research on Cancer 2012). Häufig wird die Diagnose in einem fortgeschrittenen Stadium gestellt. Das Wissen über genetische Mutationen der Tumorzellen, wie beispielsweise der EGFR-Mutation, hat die Entwicklung individueller, zielgerichteter Therapieansätze ermöglicht, die an diesen Mutationen angreifen (Shepherd et al. 2005). Die Diagnostik auf molekularer Ebene gehört deshalb heute zur Routine bei der Untersuchung von Gewebe des Bronchialkarzinoms (Chowdhuri et al. 2012). Die Diagnostik anhand von FFPE-Biopsien zeigte, dass eine spezifische EGFR-Mutation nur mit einer Sensitivität von $70 \%$ nachgewiesen werden konnte, was die Notwendigkeit weiterer Verbesserungen in der Anreicherung der Tumorzellen deutlich machte (Oxnard et al. 2016). Die steigende Inzidenz des Adenokarzinoms und seine Einteilung in Subgruppen hat eine stärkere Bedeutung der Gewebebiopsie für die Diagnose des Adenokarzinoms nach sich gezogen (Osmani et al. 2018). Mit hoher Wahrscheinlichkeit könnten DNA Mutationstests, nach Anreicherung der Tumorzellen, die Anzahl der Patienten erhöhen, die von einer gezielten Therapie profitieren könnten.

Ein wesentlicher Grund für die geringe Ausschöpfung von Tumorzellen aus dem Gewebe des Adenokarzinoms der Lunge und der somit sehr herausfordernden Mutationsanalyse, sind die oft sehr kleinen Proben des Tumorgewebes, das aus einer heterogenen Mischung von Krebszellen sowie deren umgebenden Stroma- und Immunzellen besteht, was zu falsch-negativen Analysen führen kann. Daher erfordern viele diagnostische Analysen, insbesondere der Nachweis genetischer Mutationen, eine aufwändige Zellisolation durch Mikrodissektionstechniken, um die Sensitivität und Spezifität der Analyse der Tumorzellen zu erhöhen und sensitive Ergebnisse zu erzielen. Diese Mikrodissektionsmethoden, wie beispielsweise die Laser Capture Microdissection (LCM), sind jedoch sehr zeit- und kostenaufwendig (Appleby-Mallinder et al. 2016) und fordern eine hohe Expertise.

Die von Emmert-Buck et al. beschriebene und von Hanson et al. weiter entwickelte expressionsbasierte Mikrodissektion (xMD) bietet eine weitere Form der Mikrosdissektionstechniken, die den Zeit- und Kostenfaktor minimiert (Hanson et al. 2011).

In dieser Arbeit wurde das xMD-Protokoll anhand von Gewebe des Adenokarzinoms der Lunge mit einer EGFR-Mutation reproduziert und optimiert. 
Die Ergebnisse zeigen, dass die $\mathrm{xMD}$ gegenüber den konventionellen Mikrodissektionstechniken wie der LCM entscheidende Vorteile bietet. Die Selektion der Zellen beruht auf der immunhistochemischen Markierung von Tumorzellen und stellt somit geringere Anforderungen an die Expertise des Untersuchers (Goldstein et al. 1998).

Darüber hinaus war jedoch nicht klar, ob nachfolgende Analysen wie beispielsweise DNAbasierte Methoden möglicherweise durch die xMD beeinflusst werden, weshalb sie nach der Mikrodissektion, im Vergleich zu nicht mikrodissezierten Gewebeproben, ausgewertet werden sollten (Tangrea et al. 2011). Erste Ergebnisse an neurologischen Geweben zeigten in nachfolgenden Analysen eine deutliche Anreicherung der Tumorzellen durch die xMD (Appleby-Mallinder et al. 2016).

\subsection{Optimierung der xMD am Adenokarzinom der Lunge}

Im ersten Schritt dieser Arbeit wurde die von Tangrea et al. 2004 beschriebene xMD reproduziert und am Beispiel des pulmonalen Gewebe des Adenokarzinoms optimiert.

Dazu wurden verschiedene Modifikationen an Materialien evaluiert und es zeigte sich, dass bei Verwendung des Objektträgers Superfrost Plus die Balance zwischen Haftung des Gewebes am Objektträger während der Vorbehandlung und Lösbarkeit vom Objektträger nach der Laserbehandlung optimal ist.

In den ersten Reproduktionen des Protokolls von Tangrea et al. konnten Erfolge erzielt werden, die jedoch nicht konstant blieben. Deshalb wurde die immunhistochemische, chromogene Präzipitation und damit die Färbungsintensität durch die Verwendung eines primären Anti-Cytokeratin-7-Antikörpers (CK7) in Kombination mit Vektor Black als Chromogen verbessert. Vektor Black verstärkt die Resorption der Laserenergie und verbessert dadurch die Verschmelzung von EVA-Folie und Chromogen. Der Antikörper CK7 wurde verwendet, da er eine spezifische immunhistochemische Markierung ermöglicht.

Es ist davon auszugehen, dass das Chromogen Vector Black auch die Dissektionseffizienz im Zusammenhang mit anderen Gewebeproben und Immunfärbungen erhöht, jedoch muss eine gründliche Evaluation des Protokolls für die Anwendung in anderen Geweben erfolgen.

Im Gegensatz zu dem von Tangrea et al. verwendeten Chromogen DAB konnte eine intensivere Färbung der Tumorzellen am Gewebe des Adenokarzinoms der Lunge erreicht werden. Bei darauffolgender Anwendung der xMD stellten sich erste Erfolge ein, denn die dreifache Intensivierung des dunklen Chromogens verstärkte die Wirkung des Lasers und 
führte zur Verschmelzung der Tumorzellen mit der EVA-Membran. Dies zeigt, dass die intensive Färbung mit Vektor Black in dreifacher Konzentration die expressionsbasierte Mikrodissektion am Gewebe des Adenokarzinoms der Lunge verbessert.

Durch Hinzufügen einer Wärmeplatte als Unterlage ließ sich die für die Verschmelzung von Zellen und der EVA-Membran nötige Hitzeentwicklung durch die Vorwärmung der Gewebeschnitte optimieren. Durch konstante Erwärmung wurde der Schmelzpunkt der EVA-Membran von $78^{\circ} \mathrm{C}$ schnell erreicht, sodass die hinzugefügte Energie des Lasers ausreichend war. Nun stellte sich ein konstanter Erfolg bei der Anwendung der xMD ein. Bei zu geringer Temperatur nahm die Sensitivität der xMD ab und es wurden keine oder nur kaum Tumorzellen auf die EVA-Membran transferiert. Bei zu hoher Temperatur kam es wiederum zur unspezifischen Verschmelzung der EVA-Membran mit dem Gewebe, sodass mehr Gewebe auf die EVA-Membran transferiert wurde als erwünscht.

In dem Methodenaufbau dieser Arbeit erwies sich die Temperatur der Wärmeplatte von $78^{\circ} \mathrm{C}$ als optimal für die xMD eines $10 \mu \mathrm{m}$ Gewebeschnitts, der mit Vector Black in dreifacher Konzentration immunhistochemisch behandelt wurde, sowie die Anwendung einer EVA-Membran (CoTran 9715, 3 M) aus $19 \%$ Vinyl-Acetat und von 76,2 $\mu \mathrm{m}$. Dies entspricht der von Hanson et al. 2011 beschriebenen optimalen Dicke von 50-100 $\mu \mathrm{m}$.

Die Temperatur kann jedoch bei verschiedenen Gewebeproben, verschiedenen EVAMembranen oder verschiedenen Lasergeräten variieren und muss je nach Kombination individuell angepasst werden. Durch Erwärmen einer Gewebeprobe vor der Laserbestrahlung könnte jedoch auch bei verschiedenen anderen Gewebeproben die Dissektionseffizienz erhöht werden. In der Arbeit von Appleby-Mallinder et al. 2016 wurde die xMD an kortikalem Hirngewebe von Ratten etabliert, hier erfolgte eine zehnminütige Vorwärmung des Gewebes bei $60^{\circ} \mathrm{C}$ und nach dem Aufbringen der EVA-Folie wurde dieser Schritt wiederholt, bevor die Bearbeitung mit dem Laser erfolgte.

\subsection{Digitalisierung der Objektträger}

Durch die Digitalisierung der Objektträger konnten in den letzten Jahren Fortschritte in der Bildanalyse erreicht werden, da die Quantifizierung jedes einzelnen Pixels möglich ist. So kann beispielsweise die Abnahme der Färbeintensität jedes Pixels vor und nach der Mikrodissektion gemessen und so die Effizienz der xMD bewertet werden. Eine Reduzierung der Färbeintensität kann quantitativ für jeden einzelnen Pixel nachgewiesen werden (Grafen et al. 2017). 
Während der Durchführung der xMD kann bei verschiedenen Schritten der Erfolg der Methode bewertet werden; die Anwendung des Lasers führt zur Verschmelzung der EVAFolie mit dem Chromogen auf den Tumorzellen, der Erfolg wird durch eine feucht wirkende Veränderung des laserbestrahlten Bereichs beobachtet. Der Transfer der Tumorzellen kann durch die mikroskopische Untersuchung vor und nach der xMD beurteilt werden.

Diese Beobachtungen lassen sich durch die digitale Bildanalyse der Objektträger quantifizieren, die in dieser Arbeit anschließend an die xMD durchgeführt wurde.

Die Visualisierung der Ergebnisse durch Histogramme zeigte vor der Laseranwendung Objektträger mit schwächer gefärbten Anteilen (wenig Tumorzellen) neben stark gefärbten Arealen (tumorzellreiche Areale). Nach Anwendung des Lasers und Entfernung der EVAFolie, zeigten die initial intensiver gefärbten Bereiche eine starke Reduktion der Färbeintensität. Daraus lässt sich schließen, dass hauptsächlich die dunkel gefärbten Tumorzellen transferiert wurden, während die leicht gefärbten und nicht-neoplastisch veränderten Zellen auf dem Objektträger verblieben.

In einigen Proben kam es jedoch auch in den weniger intensiv gefärbten Arealen zur minimalen Abnahme der Färbeintensität sowie zur ausbleibenden Abnahme der Farbintensität der stärker gefärbten Anteile, was für eine unspezifische xMD spricht und hier weitere Optimierungen in der Handhabung des Lasers notwendig macht.

In Streudiagrammen ließ sich mithilfe einer unbehandelten Simulationskontrolle nachweisen, dass ohne die direkt zugeführte Laserenergie der Transfer des Gewebes ausbleibt. Im Vergleich zeigten Streudiagramme einer anschließenden Reihe von Proben nach Anwendung der Laserenergie eine Mediane, die eine Abnahme der Färbeintensität abbildete und somit den Tumorzelltransfer aufzeigte.

Durch wiederholtes Scannen und dadurch leicht abweichende Bildausrichtungen wurden kleine Abweichungen verursacht. Dies zeigt, dass jeder direkte Effekt auf das Bild eine potentielle Abweichung der Mediane birgt.

Die digitale Bildanalyse stellte in dieser Arbeit die Möglichkeit der präzisen Evaluation des Zelltransfers vor und nach der xMD sicher, so konnte die Sensitivität und Effizienz der Methode belegt werden.

\subsection{Analyse der DNA}

In der Arbeit von Tangrea et al. wurde auf weiterführende Untersuchungen, wie die DNAAnalyse hingewiesen, die durch die Vorbehandlung der Proben beeinflusst werden kann, 
weshalb nach erfolgter Mikrodissektion die Kontrolle mit unbehandelten Proben durchgeführt werden sollte (Tangrea et al. 2011).

Im letzten Schritt dieser Arbeit wurde die DNA-Qualität der isolierten Tumorzellen getestet, um eine fragliche Schädigung der DNA-Qualität durch die Immunhistochemie oder durch die Laserenergie zu beurteilen.

Dazu wurden die Zellen von der EVA-Folie isoliert und mittels digitaler PCR quantifiziert. Es konnte eine mittlere DNA-Fragmentlänge von 650 Basenpaaren gemessen werden, was mit der DNA-Menge formalin-fixierter Gewebeproben, die keiner Vorbehandlung zugeführt wurden, vergleichbar ist (Grafen et al. 2017).

Im Vergleich war die DNA-Menge nach Isolation der Tumorzellen von der EVA-Folie geringer als die DNA-Menge der Kontrollen, die keiner xMD unterzogen wurden. Dies ist durch die Zellisolation und den somit geringeren Zellgehalt an der EVA-Folie zu erklären. Die geringere Menge an DNA war für die digitale PCR aber ausreichend für die Amplifikation und Quantifikation eines 91bp Amplicons.

Chemisch modifizierte und/oder fragmentierte Templatemoleküle können durch die Formalinfixierung zur Bildung von Tröpfchen führen, was sich in der Auswertung der PCR durch ein „Regenphänomen“ widerspiegelt.

In der digitalen PCR von unbehandelten formalin-fixierten Proben und Proben mit dem verbleibenden Gewebe auf den Objektträgern nach der xMD, fand sich kein Unterschied in der Ausprägung des Regenphänomens, was zu der Annahme führte, dass die Qualität der DNA sich weder durch die Immunhistochemie, noch durch die Laserbehandlung ändert.

Es konnte gezeigt werden, dass die xMD eine Methode zur Anreicherung homogener EGFR-mutierter Tumorzellen bietet. Da die EGFR-Mutation nur ein Allel der DNA betrifft, lässt sich die Effizienz der Methode auch durch das Verhältnis von EGFRmutierter DNA zu Wild-Typ-EGFR abschätzen (Li et al. 2008).

Zusammenfassend lässt sich schlussfolgern, dass die durch die Formalinfixierung, Vorbehandlung und xMD fragmentierte und chemisch modifizierte DNA für weitere diagnostische und wissenschaftliche Analysen geeignet ist und durch die xMD ein homogenes Ausgangsmaterial gewonnen werden kann. 


\subsection{Ausblick}

Die Fortschritte im Verständnis der Tumorgenetik können die Prognose der Tumorpatienten durch die zielgerichtete Therapie, basierend auf dem molekularen Profil des Tumors, verbessern. Dies macht die xMD zu einem wichtigen Tool der pathologischen Diagnostik und ebnet den Weg der Präzisionsmedizin (Rosenberg et al. 2016). Sie vereinfacht die Isolation spezifischer Zellpopulationen, da die mikroskopische Zellidentifikation entfällt.

Anhand der in dieser Arbeit gewonnen Erkenntnisse hat sich bestätigt, dass der Erfolg der xMD stark von der Intensität der immunhistochemischen Färbung sowie der angewandten Laserenergie abhängt (Grover et al. 2006; Hanson et al. 2006; Du et al. 2013) und die xMD sich neben den in bestehenden Studien auch an anderen Geweben etablieren lässt.

Je nach Gewebe ist jedoch eine Anpassung des Protokolls nötig. Dies betrifft die entsprechende Vorbehandlung mit der Auswahl des Objektträgers, die Festlegung der Gewebedicke, die Anpassung der Immunhistochemie, insbesondere der Antikörper an das Gewebe, sowie die Intensität des Chromogens und der angewendeten Laserenergie.

In den einzelnen Schritten des Protokolls sind weitere Optimierungen denkbar, um mögliche Fehlerquellen zu minimieren und die xMD so weiter zu entwickeln. Die immunhistochemische Vorbehandlung kann zum Beispiel durch einen programmierten Färbeautomat durchgeführt werden, so dass eine einheitliche und spezifische Färbung erreicht wird.

Ein weiterer Optimierungsschritt kann in der Handhabung des Lasers entwickelt werden, indem für die Zufuhr der Laserenergie automatisierte Blitzlampen anstelle des manuellen SDL-15 Lasersystems verwendet werden. Die Gewebeflächen könnten hier unter einer konstanten und präzisen Flussrate bestrahlt werdend, jedoch muss auch hier die Laserenergie sowie die Vorwärmung des Gewebe und der aufliegenden EVA-Folie an jeden neuen Gewebekontext angepasst werden (Blackler et al. 2013).

Abschließend wird mit dieser Arbeit ein optimiertes xMD-Protokoll für das Adenokarzinom der Lunge angeboten, welches die Optimierung der Gewebevorbehandlung, der Immunhistochemie und der Probenhandhabung beschreibt.

Mit der DNA-Analyse und durch das Slide-Scanning konnte die Methode evaluiert und die Spezifität, Sensitivität und Reproduzierbarkeit der xMD dargelegt werden. 
Das in dieser Arbeit etablierte und optimierte Protokoll der xMD kann für verschiedene weiterführende wissenschaftliche und diagnostische Analysen verwendet werden und als Grundlage für weitere darauf basierende Verfahren dienen. 


\section{Zusammenfassung}

In der Präzisionsmedizin von Tumoren ist die Analyse spezifischer DNA-Veränderungen für die gezielte Therapie von entscheidender Bedeutung. Lungenkrebs stellt ein prototypisches Beispiel dar und ist zudem eine der führenden Ursachen für krebsbedingte Todesfälle weltweit.

Der epidermal growth factor rezeptor (EGFR) kann unter anderem beim Adenokarzinom der Lunge mutiert sein. Die Mutation des Rezeptors führt zum ungehemmten Wachstum der Zellen weshalb sie einen Angriffspunkt für EGFR-spezifische Therapien bietet.

Ein großes technisches Problem beim Nachweis von DNA-Veränderungen in Gewebeproben ist die zelluläre Heterogenität, also die Einbettung von Tumorzellen in verschiedene nicht-neoplastische Zellpopulationen des Mikromilieus. Die Mikrodissektion ist ein wichtiges Werkzeug zur Anreicherung von Tumorzellen aus heterogenen Gewebeproben. Die konventionelle Laser Capture Mikrodissektion hat jedoch mehrere Nachteile, wie zum Beispiel die benutzerabhängige Detektion der Zielzellen sowie hohe Kosten für Dissektionssysteme und lange Verarbeitungszeiten. Die expressionsbasierte Mikrodissektion (xMD) verwendet die Immunhistochemie für die möglichst selektive Anfärbung von Krebszellen. Die Laserbehandlung der immunhistochemisch gefärbten Gewebeschnitte führt zu einer lokalen Energieabsorption an den Stellen der intensivsten Färbung und zur Schmelzung einer den Objektträger bedeckenden Membran, sodass durch die Entfernung der kompletten Membran die Tumorzellen wie durch ein Abziehbild isoliert werden können.

In dieser Arbeit wurde die xMD an Lungenkarzinomgewebe optimiert und die immunhistochemische Färbungsintensität der Tumorzellen und die Verarbeitung der gefärbten Proben untersucht. Das optimierte Verfahren führt zur Anreicherung von mutierter EGFR-DNA aus Proben des Adenokarzinoms der Lunge nach der xMD und ändert dabei die DNA-Qualität nicht. Weiter wird ein qualitätskontrollierendes Protokoll vorgestellt, das auf der digitalen Bildanalyse vor und nach der xMD basiert und die Selektivität und Effizienz des Verfahrens quantifiziert.

Zusammenfassend bietet diese Arbeit ein Protokoll für die xMD, das anhand von Gewebe des Adenokarzinoms der Lunge optimiert und geprüft wurde und für die Präparation von Tumorzellen des Lungenkarzinoms vor diagnostischen oder investigativen Analysen verwendet werden kann. 


\section{Literaturverzeichnis}

Alberg AJ, Brock MV, Ford JG, Samet JM, Spivack SD (2013): Epidemiology of lung cancer: Diagnosis and management of lung cancer, 3rd ed: American College of Chest Physicians evidence-based clinical practice guidelines. Chest 143

Appleby-Mallinder C, Wyles MD, Simpson JE, Wharton SB, Ince PG, Heath PR (2016): Expression microdissection isolation of enriched cell populations from archival brain tissue. J Neurosci Methods 268, 125-130

Banks RE, Dunn MJ, Forbes MA, Stanley A, Pappin D, Naven T, Gough M, Harnden P, Selby PJ (1999): The potential use of laser capture microdissection to selectively obtain distinct populations of cells for proteomic analysis--preliminary findings. Electrophoresis 20, 689-700

Barnes B, Kraywinkel K, Nowossadeck E, Schönfeld I, Starker A, Wienecke A, Wolf U: Bericht zum Krebsgeschehen in Deutschland 2016. Robert Koch-Institut 2016

Blackler AR, Morgan NY, Gao B, Olano LR, Armani MD, Romantseva E, Kakareka JW, Bonner RF, Mukherjee S, Xiao B. et al. (2013): Proteomic analysis of nuclei dissected from fixed rat brain tissue using expression microdissection. Anal Chem 85 7139-7145

Bob A, Bob K: Duale Reihe Innere Medizin. 3. Auflage; Thieme Verlag, Stuttgart 2012

Böcker W: Pathologie. 4. Auflage; Elsevier GmbH, München 2008

Bonner RF, Emmert-Buck M, Cole K, Pohida T, Chuaqui R, Goldstein S, Liotta LA (1997): Laser capture microdissection: molecular analysis of tissue. Science 278, 1481, 1483

Chowdhuri SR, Xi L, Pham THT, Hanson J, Rodriguez-Canales J, Berman A, Rajan A, Giaccone G, Emmert-Buck M, Raffeld M et al. (2012): EGFR and KRAS mutation analysis in cytologic samples of lung adenocarcinoma enabled by laser capture microdissection. Mod Pathol Off J U S Can Acad Pathol Inc 25, 548-555

Ciardiello F, de Vita F, Orditura M, Tortora G (2004): The role of EGFR inhibitors in nonsmall cell lung cancer. Curr Opin Oncol 16, 130-135

Cooper WA, Lam DCL, O’Toole SA, Minna JD (2013): Molecular biology of lung cancer. J Thorac Dis $\underline{5}, 479-490$

D’Addario G, Felip E (2009): Non-small-cell lung cancer: ESMO Clinical Recommendations for diagnosis, treatment and follow-up. Ann Oncol 20, 
Didelot A, Kotsopoulos SK, Lupo A, Pekin D, Li X, Atochin I, Srinivasan P, Zhong Q, Olson J, Link DR et al. (2013): Multiplex picoliter-droplet digital PCR for quantitative assessment of DNA integrity in clinical samples. Clin Chem $\underline{59}, 815-823$

Du Q, Yan W, Burton VH, Hewitt SM, Wang L, Hu N, Taylor PR, Armani MD, Mukherjee S, Emmert-Buck MR et al. (2013): Validation of esophageal squamous cell carcinoma candidate genes from high-throughput transcriptomic studies. Am J Cancer Res $\underline{3}, 402-410$

Emmert-Buck MR, Bonner RF, Smith PD, Chuaqui RF, Zhuang Z, Goldstein SR, Weiss RA, Liotta LA (1996): Laser capture microdissection. Science 274, 998-1001

Fukuoka M, Wu YL, Thongprasert S, Sunpaweravong P, Leong SS, Sriuranpong V, Chao T-Y, Nakagawa K, Chu D-T, Saijo N et al. (2011): Biomarker analyses and final overall survival results from a phase III, randomized, open-label, first-line study of gefitinib versus carboplatin/paclitaxel in clinically selected patients with advanced non-small-cell lung cancer in Asia (IPASS). J Clin Oncol Off J Am Soc Clin Oncol 29, 2866-2874

Goldstein SR, McQueen PG, Bonner RF (1998): Thermal modeling of laser capture microdissection. Appl Opt 37, 7378-7391

Grafen M, Hofmann TR, Scheel AH, Beck J, Emmert A, Kuffer S, Danner BC, Schutz E, Buttner R, Ostendorf A et al. (2017): Optimized expression-based microdissection of formalin-fixed lung cancer tissue. Lab Investig J Tech Methods Pathol 97, 863-872

Grover AC, Tangrea MA, Woodson KG, Wallis BS, Hanson JC, Chuaqui RF, Gillespie JW, Erickson HS, Bonner RF, Pohida TJ et al. (2006): Tumor-associated endothelial cells display GSTP1 and RAR $\beta 2$ promoter methylation in human prostate cancer. J Transl Med $\underline{4}, 13$

Han JY, Park K, Kim S-W, Lee DH, Kim HY, Kim HT, Ahn MJ, Yun T, Ahn JS, Suh C et al. (2012): First-SIGNAL: first-line single-agent iressa versus gemcitabine and cisplatin trial in never-smokers with adenocarcinoma of the lung. J Clin Oncol Off J Am Soc Clin Oncol 30, 1122-1128

Hanson JA, Gillespie JW, Grover A, Tangrea MA, Chuaqui RF, Emmert-Buck MR, Tangrea JA, Libutti SK, Linehan WM, Woodson KG (2006): Gene promoter methylation in prostate tumor-associated stromal cells. J Natl Cancer Inst 98, 255-261

Hanson JC, Tangrea MA, Kim S, Armani MD, Pohida TJ, Bonner RF, Rodriguez-Canales J, Emmert-Buck MR (2011): Expression microdissection adapted to commercial laser 
dissection instruments. Nat Protoc $\underline{6}, 457-467$

Jorge S, Kobayashi S, Costa D (2014): Epidermal growth factor receptor (EGFR) mutations in lung cancer: preclinical and clinical data. Braz J Med Biol Res 47, 929-939

Keedy VL, Temin S, Somerfield MR, Beasley MB, Johnson DH, McShane LM, Milton DT, Strawn JR, Wakelee HA, Giaccone G (2011): American Society of Clinical Oncology provisional clinical opinion: epidermal growth factor receptor (EGFR) Mutation testing for patients with advanced non-small-cell lung cancer considering first-line EGFR tyrosine kinase inhibitor therapy. J Clin Oncol Off J Am Soc Clin Oncol 29, 2121-2127

Li AR, Chitale D, Riely GJ, Pao W, Miller VA, Zakowski MF, Rusch V, Kris MG, Ladanyi M (2008): EGFR Mutations in Lung Adenocarcinomas. J Mol Diagn JMD 10, 242-248

Lynch TJ, Bell DW, Sordella R, Gurubhagavatula S, Okimoto RA, Brannigan BW, Harris PL, Haserlat SM, Supko JG, Haluska FG, et al. (2004): Activating mutations in the epidermal growth factor receptor underlying responsiveness of non-small-cell lung cancer to gefitinib. N Engl J Med 350, 2129-2139

Maemondo M, Inoue A, Kobayashi K, Sugawara S, Oizumi S, Isobe H, Gemma A, Harada M, Yoshizawa H, Kinoshita I, et al. (2010): Gefitinib or chemotherapy for non-small-cell lung cancer with mutated EGFR. N Engl J Med 362, 2380-2388

Mok TS, Wu YL, Thongprasert S, Yang CH, Chu D-T, Saijo N, Sunpaweravong P, Han B, Margono B, Ichinose Y et al. (2009): Gefitinib or carboplatin-paclitaxel in pulmonary adenocarcinoma. N Engl J Med 361, 947-957

Nicholson RI, Gee JM, Harper ME (2001): EGFR and cancer prognosis. Eur J Cancer Oxf Engl 1990 37, 9-15

Osmani L, Askin F, Gabrielson E, Li QK (2018): Current WHO guidelines and the critical role of immunohistochemical markers in the subclassification of non-small cell lung carcinoma (NSCLC): Moving from targeted therapy to immunotherapy. Semin Cancer Biol 52, 103-109

Oxnard GR, Thress KS, Alden RS, Lawrance R, Paweletz CP, Cantarini M, Yang JC-H, Barrett JC, Jänne PA (2016): Association Between Plasma Genotyping and Outcomes of Treatment With Osimertinib (AZD9291) in Advanced Non-Small-Cell Lung Cancer. J Clin Oncol Off J Am Soc Clin Oncol 34, 3375-3382

Pao W, Miller V, Zakowski M, Doherty J, Politi K, Sarkaria I, Singh B, Heelan R, Rusch V, Fulton L et al. (2004): EGF receptor gene mutations are common in lung cancers from 
„never smokers“ and are associated with sensitivity of tumors to gefitinib and erlotinib. Proc Natl Acad Sci U S A 101, 13306-13311

Prabhakar CN (2015): Epidermal growth factor receptor in non-small cell lung cancer. Transl Lung Cancer Res $\underline{4}, 110-118$

Rosell R, Carcereny E, Gervais R, Vergnenegre A, Massuti B, Felip E, Palmero R, GarciaGomez R, Pallares C, Sanchez JM et al. (2012): Erlotinib versus standard chemotherapy as first-line treatment for European patients with advanced EGFR mutation-positive nonsmall-cell lung cancer (EURTAC): a multicentre, open-label, randomised phase 3 trial. Lancet Oncol 13, 239-246

Rosenberg AZ, Armani MD, Fetsch PA, Xi L, Pham T'T, Raffeld M, Chen Y, O'Flaherty N, Stussman R, Blackler AR et al. (2016): High-Throughput Microdissection for NextGeneration Sequencing. PloS One 11, e0151775

Sakai Y, Nakai T, Ohbayashi C, Imagawa N, Yanagita E, Satake R, Nitta A, Kajimoto K, Sakuma T, Itoh T (2013): Immunohistochemical profiling of ALK fusion gene-positive adenocarcinomas of the lung. Int J Surg Pathol 21, 476-482

Sanchez-Cespedes M, Ahrendt SA, Piantadosi S, Rosell R, Monzo M, Wu L, Westra WH, Yang SC, Jen J, Sidransky D (2001): Chromosomal alterations in lung adenocarcinoma from smokers and nonsmokers. Cancer Res $\underline{61}, 1309-1313$

Shepherd FA, Rodrigues Pereira J, Ciuleanu T, Tan EH, Hirsh V, Thongprasert S, Campos D, Maoleekoonpiroj S, Smylie M, Martins R et al. (2005): Erlotinib in previously treated non-small-cell lung cancer. N Engl J Med $\underline{353}, 123-132$

Soda M, Choi YL, Enomoto M, Takada S, Yamashita Y, Ishikawa S, Fujiwara S, Watanabe H, Kurashina K, Hatanaka H, et al. (2007): Identification of the transforming EML4-ALK fusion gene in non-small-cell lung cancer. Nature $\underline{448}, 561-566$

Tangrea MA, Chuaqui RF, Gillespie JW, Ahram M, Gannot G, Wallis BS, Best CJM, Linehan WM, Liotta LA, Pohida TJ et al. (2004): Expression microdissection: operatorindependent retrieval of cells for molecular profiling. Diagn Mol Pathol Am J Surg Pathol Part B $\underline{13}, 207-212$

Tangrea MA, Mukherjee S, Gao B, Markey SP, Du Q, Armani M, Kreitman MS, Rosenberg AM, Wallis BS, Eberle FC et al. (2011): Effect of immunohistochemistry on molecular analysis of tissue samples: implications for microdissection technologies. J Histochem Cytochem Off J Histochem Soc 59, 591-600 
The Cancer Genome Atlas Research Network (2012): Comprehensive genomic characterization of squamous cell lung cancers. Nature $\underline{489}, 519-525$

The Cancer Genome Atlas Research Network (2014): Comprehensive molecular profiling of lung adenocarcinoma. Nature $\underline{511}, 543-550$

Travis WD, Brambilla E, Nicholson AG, Yatabe Y, Austin JHM, Beasley MB, Chirieac LR, Dacic S, Duhig E, Flieder DB et al. (2015): The 2015 World Health Organization Classification of Lung Tumors: Impact of Genetic, Clinical and Radiologic Advances Since the 2004 Classification. J Thorac Oncol Off Publ Int Assoc Study Lung Cancer 10, 12431260

Vi N, Ma Z, Fields T, Avliyakulov N, Haykinson M, Bragin A, Kudo L, Karsten S (2012): New Low Cost Cell and Tissue Acquisition System (CTAS): Microdissection of Live and Frozen Tissues. J Biomol Tech JBT $\underline{23}$

Wang M, Zhao J, Zhang L, Wei F, Lian Y, Wu Y, Gong Z, Zhang S, Zhou J, Cao K et al. (2017): Role of tumor microenvironment in tumorigenesis. J Cancer $\underline{8}, 761-773$

Warth A, Muley T, Herpel E, Meister M, Herth FJF, Schirmacher P, Weichert W, Hoffmann H, Schnabel PA (2012): Large-scale comparative analyses of immunomarkers for diagnostic subtyping of non-small-cell lung cancer biopsies. Histopathology $\underline{61}, 1017-$ 1025

Wells A (1999): EGF receptor. Int J Biochem Cell Biol 31, 637-643

Wu YL, Zhou C, Liam CK, Wu G, Liu X, Zhong Z, Lu S, Cheng Y, Han B, Chen L et al. (2015): First-line erlotinib versus gemcitabine/cisplatin in patients with advanced EGFR mutation-positive non-small-cell lung cancer: analyses from the phase III, randomized, open-label, ENSURE study. Ann Oncol Off J Eur Soc Med Oncol 26, 1883-1889

Yano T, Haro A, Shikada Y, Maruyama R, Maehara Y (2011): Non-small cell lung cancer in never smokers as a representative „non-smoking-associated lung cancer“: epidemiology and clinical features. Int J Clin Oncol 16, 287-293

Zhou C, Wu YL, Chen G, Feng J, Liu XQ, Wang C, Zhang S, Wang J, Zhou S, Ren S, et al. (2011): Erlotinib versus chemotherapy as first-line treatment for patients with advanced EGFR mutation-positive non-small-cell lung cancer (OPTIMAL, CTONG-0802): a multicentre, open-label, randomised, phase 3 study. Lancet Oncol 12, 735-742

International Agency for Research on Cancer. http://gco.iarc.fr/; Zugriff am 19.10.2018 Statistisches Bundesamt (Destatis), URL: 
https://www.destatis.de/DE/ZahlenFakten/GesellschaftStaat/Gesundheit/Todesursache

n/Tabellen/SterbefaelleInsgesamt.html, abgerufen am: 04.01.2018 


\section{Danksagung}

Bedanken möchte ich mich bei Prof. Dr. Philipp Ströbel, der mir diese Promotion ermöglicht hat. Für sein Vertrauen, das er in mich und meine Arbeit gesetzt hat und für die Freiheiten, die er mir bei der Erarbeitung dieses Projektes gelassen hat.

Dr. Hanibal Bohnenberger möchte ich danken für die großartige Betreuung während der vergangenen Jahre, sowie für die technische Umsetzung im Labor und dass ich ihn stets um Rat fragen konnte.

Für die Unterstützung in der Aufarbeitung und Analyse der DNA möchte ich Dr. Julia Beck danken.

Dr. Andreas Scheel danke ich für die Unterstützung in der Digitalisierung der Objektträger und der Bildanalyse.

Mein besonderer Dank gilt meiner Familie und Karl Gridl, die mich in meiner täglichen Arbeit unterstützen. Ich widme diese Arbeit meiner Großmutter und meinem Vater. 
